


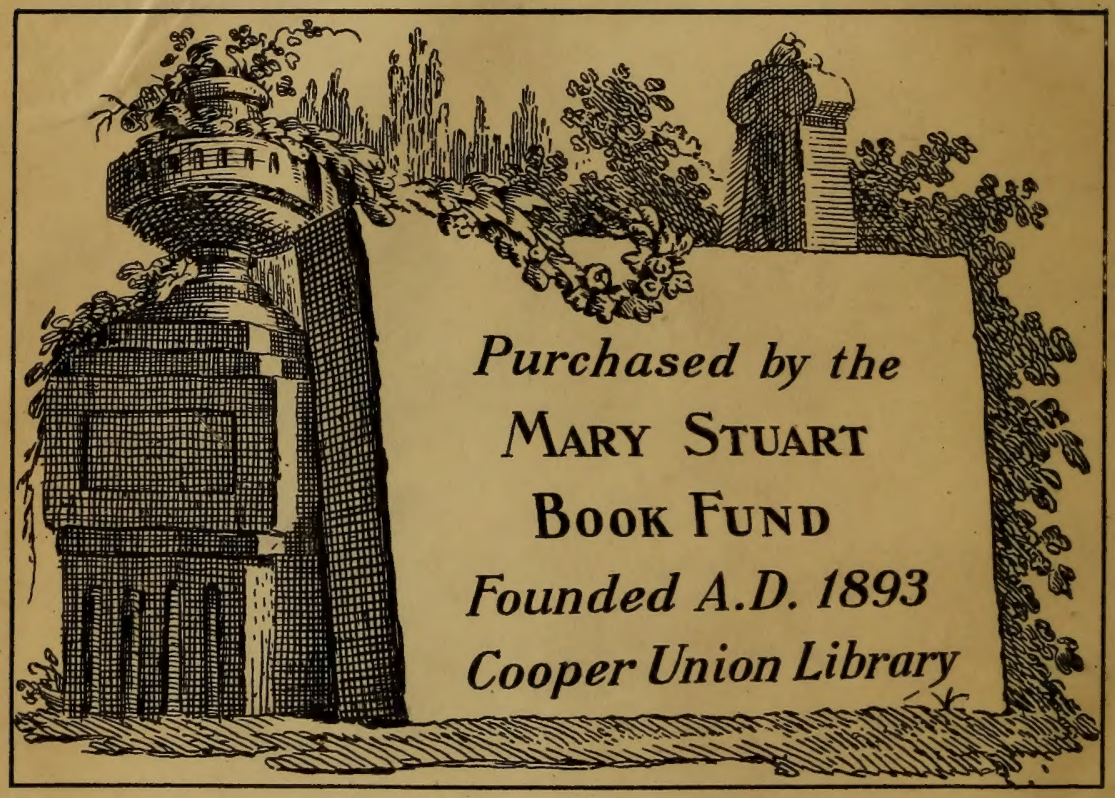




REPOUSSÉ METALWORK 


\section{TEXT-BOOKS OF TECHNOLOGY}

Edited by Prof. J. Wertheimer, B.Sc., B.A., F.I.C., F.C.S., Principal of the Merchant Venturers' Technical College, Bristol.

Messrs. Methuen and Co. are issuing a series of elementary books under the above title. They are specially adapted to the needs of Technical Schools and Colleges, and fulfil the requirements of Students preparing for the Examinations of the City and Guilds of London Institute.

The prices vary according to the size of the volumes, which are suitably illustrated, and are provided with numerous examples and examination papers.

HOW TO MAKE A DRESS. By Miss Wood, Chief Instructress at the Goldsmiths' Institute, New Cross. Crown 8vo. Third Edition. Is. $6 d$.

CARPENTRY AND JOINERY. By F. C. WeBBER, Chief Lecturer to the Building Trades' Department of the Merchant Venturers' Technical College, Bristol. Crown 8vo. Third Edition. 3s. $6 d$.

PRACTICAL MEChanics. By S. H. Wells, Principal of the Battersea Polytechnic Institute. Crown 8vo. Second Edition. 3s.6d.

PRACTICAL PHYSiCS. By H. Stroud, D.Sc., M.A., Professor of Physics in the Durham College of Science, Newcastle-on-Tyne. Crown 8vo. 3s. $6 d$.

MILLINERY, THEORETICAL AND PRACTICAL. By Miss C. HiLl, Instructress to the West Riding County Council and the City of Leeds Educational Committee. Second Edition. Enlarged. Crown 8vo. 2s.

PRACTICAL Chemistry. Part I. By W. French, M.A., Principal of the Storey Institute, Lancaster. Second Edition. Crown 8vo. Is. $6 d$.

PRACTICAL CHEMISTRY. Part II. By W. FRENCH, M.A., and T. H. BOARDMAN, M.A., Science Master, Christ's Hospital. Crown 8vo. Is. $6 d$.

TECHNICAL ARITHMETIC AND GEOMETRY FOR USE IN TECHNICAL INSTITUTES. By C. T. Millis, M.I.M.E., Principal of the Borough Polytechnic Institute, London. Crown 8 vo. $3 s .6 d$.

BUILDERS' QUANTITIES. By HERBERT C. GRUBb, Lecturer in Quantities to the Beckenham Technical Institute, First Class Honours City and Guilds of London Institute. Crown 8vo. $4 s, 6 d$.

AN INTRODUCTION TO THE STUDY OF TEXTILE DESIGN. By A. F. BARKER, Head of the Department of Textile Industries, Bradford Technical College. Demy 8vo. 7s. $6 d$.

REPOUSSÉ METALWORK. By A. C. HoRTh, Master of the Art and Manual Training Departments, Roan School for Boys, Greenwich. Crown 8vo. 2s. $6 d$. 



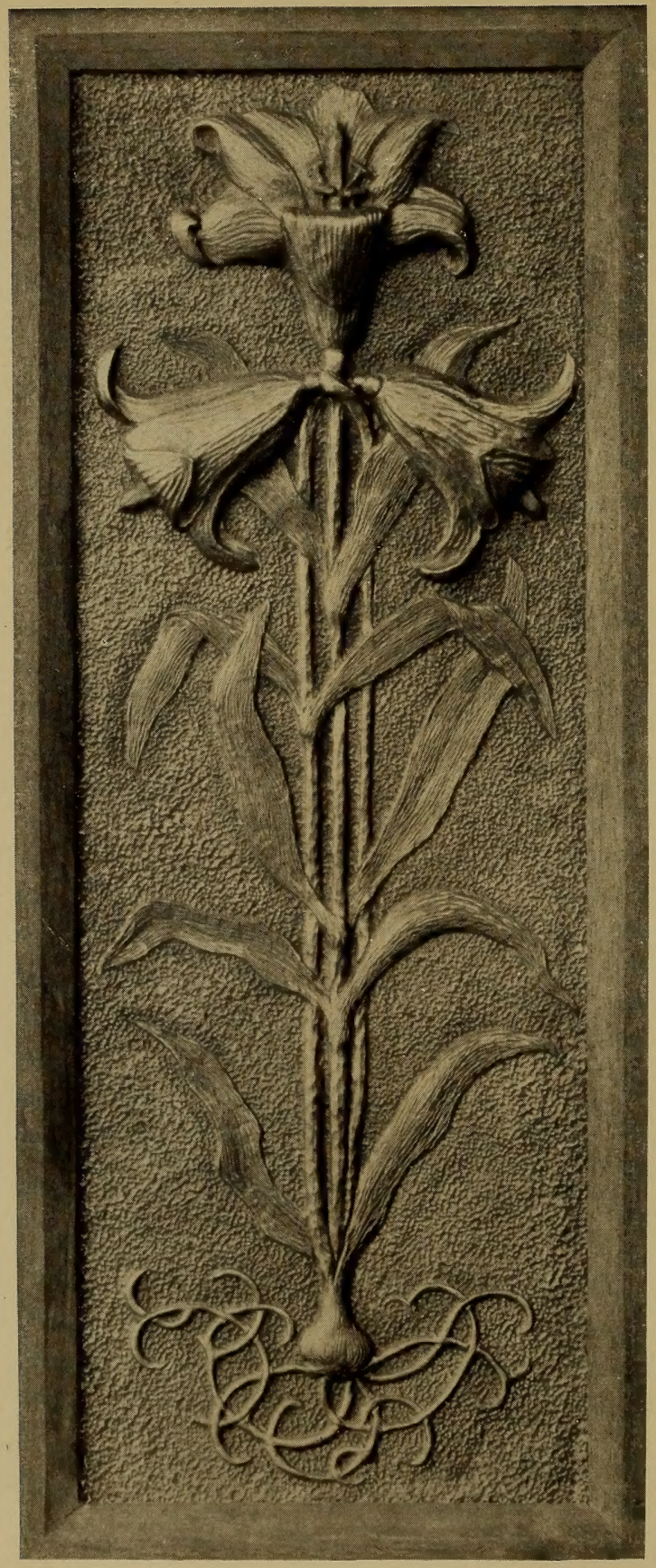

REPOUSSÉ PANEL IN HIGH RELIEF 
H67

1905

REPOUSSÉ CHM

\section{METALWORK}

A SCHEME OF SHEET METALWORK FOR SCHOOLS AND AMATEURS

BY

\section{A. C. HORTH}

INSTRUCTOR OF METALWORK (REPOUSSE) EVENING CONTINUATION SCHOOLS LONDON COUNTY COUNCIL

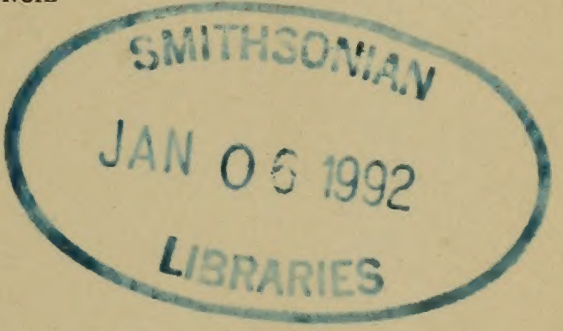

WITH DIAGRAMS AND EIGHT PLATES

METHUEN \& CO.

36 ESSEX STREET W.C.

LONDON 
First Published in 1905 


\section{CONTENTS}

Historical

PAGE

The Tools Used in Repoussé Metalwork 。 4 Appliances and Materials • • . i 6 Metal Suitable for Repoussé • • 23

EXERCISE

I. A Square Mat . . 26

II. A Square Tray • • 35

III. An Octagonal Tray . . . 40

IV. A Finger Plate - . • 43

V. A Round Tray . . 48

VI. A Matchbox Holder . . . 54

VII. A Finger Plate . . . 60

VIII. A LETTER RACK . . . 67

IX. A PEN REST . . . . 7 I

X. A Gong . . . . 75

XI. A Photo Frame - . 79

XII. A SCONCE • . . . 83

XIII. A Salver . . . . 87

XIV. A Decorative Panel . • . 90

XV. A Postcard Rack . . . 94

XVI. An Elliptical Tray • • . 96

XVII. A “Bee” Clock Case . • • 98

XVIII. A Thermometer Stand • . iOZ

A 2 



\section{INTRODUCTION}

M ETALWORKING, especially that I form of it treated in this book, has long been in the front rank of manual training subjects.

Many reasons can be given why it has become such a favourite form of hand and eye training, but chief amongst them is its comparative cheapness in working, owing to the small and inexpensive stock of tools required, compared with either woodwork or metal turning and forging.

The tool operations are divided into stages, each forming a separate model or article, which may be put to some practical use, this fact alone serving as a great inducement to take up the subject thoroughly. 
The models are carefully graded and lead from one tool operation to another, so that the great difficulties which would be experienced in beginning with a complicated piece of work are not felt at all, and the student finds himself gradually mastering the methods of work, as well as making a collection of useful articles.

The scheme as set forth in these pages has been taught with great success, the students taking much interest in the subject, owing probably to the fact that the models are attractive. It is recognised by the Board of Education as a suitable form of manual training for schools and classes on which they pay a grant.

Amateurs will find, if they carefully work through the course and follow the directions, they will gain a good knowledge of the tools and materials without the necessity of attending a class in the subject. 
Teachers will find the book useful in providing for their students a carefully graded scheme of work, and containing all the information necessary to those wishing to become expert in the work.

A. C. $\mathrm{H}$. 



\section{LIST OF PLATES}

REPOUSSÉ PANEL IN HIGH RELIEF.

A SQUARE MAT, FOUR STAGES AN OCTAGONAL TRAY, BOTH SIDES . TWO FINGER PLATES

A ROUND TRAY, BOTH SIDES

A MATCHBOX HOLDER, BOTH SIDES . REPOUSSÉ PANEL IN HIGH RELIEF, REVERSE SIDE a CIRCULAR PLAQUE

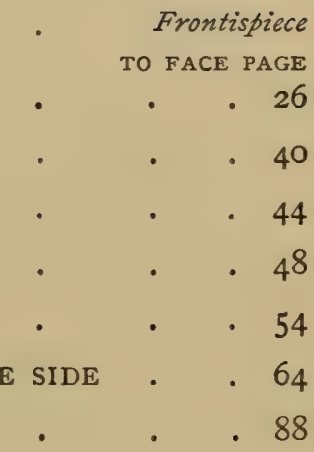

Frontispiece 26 40 44 $4^{8}$ 54 64

\section{LIST OF LLUSTRATIONS IN THE TEXT}

FIG.

I. REPOUSSÉ HAMMER

2. HAMMER

3. REPOUSSÉ MALLET

4. TRACER

5. RAISING TOOLS

6. RAISING TOOLS

7. PEARLS

8. REPOUSSÉ PUNCHES

9. MATTING TOOLS

IO. SCRIBING POINT

II. PAIR OF COMPASSES
PAGE

4

5

5

6

7

8

8

- 9

- 9

- IO

II 


\section{xii LIST OF ILLUSTRATIONS}

FIG.

I2. BURNISHER .

I2 $\alpha$. BURNISHER .

I3. PINCERS

I4. ROUND-NOSE PLIERS

I5. TRY SQUARE

I6. SHEARS

I7. DRILL

I8. STAKE, OR ANVIL

19. A TABLE

20. BENZOLINE LAMP

2I. BLOW-FLAME

22. LEATHER OR CANVAS SANDBAG

23. PITCH LADLE

24. TRAY FOR PITCH

25. SECTION THROUGH PITCH BLOCK, WITH FIXED METAL 30

26. METHOD OF HOLDING TRACER AND HAMMER • . 30

27. METHOD OF USING TRACER • . . 3 3 I

28. CORRECT AND INCORRECT METHODS OF TRACING A LINE 32

29. METHOD OF USING SANDBAG • • • . 44

30. PLAIN "BOSS" . $\quad$ - $\quad$. 53

31. UNDERCUT "BOSS" • $\quad$ • $\quad$ • 59

32 and 33. BLOCKS FOR BENDING TRAY EDGE . . 97 


\section{REPOUSSÉ METALWORK}

\section{HISTORICAL}

Cunning workers in metal existed in remote ages, and some excellent examples of their work are to be found in many of our museums.

In the days of the Greeks and Romans much attention was paid to metalworking, the craftsmen of that time attaining a high degree of skill, especially in the making of jewellery, ornaments, and shields, etc. From this time to the fourteenth and fifteenth centuries, very little was done in the work outside Italy, but gradually these centuries witnessed a great revival in metalworking, 
especially Repoussé, and many valuable examples of this period exist, especially the elaborate and beautiful Repoussé work in the churches.

In modern days machinery has been introduced, and is the cause of a great decline in the number of metal craftsmen; but for artistic work, the work of those craftsmen who still practise this ancient art compares most favourably with that of their predecessors.

The popularity of modern art furniture has led many art craftsmen to take up the fascinating study and practice of Repoussé work, and much may be done by workers in the craft towards beautifying their own homes.

Much may be learnt from the beautiful and intricate examples made by the native craftsmen of India, who from the earliest times have been famous for their work. The South Kensington Museum contains 
some of the finest specimens of Indian work in the world, and the Repoussé worker could not do better than spend an hour or two examining the perfect examples of antique and modern work exhibited there. 


\section{THE TOOLS USED IN REPOUSSÉ METALWORK}

Hammers (Figs. I and 2). A Repoussé worker's hammer is quite a different type to that of either the carpenter or mechanic. The head is smaller, but has a larger and

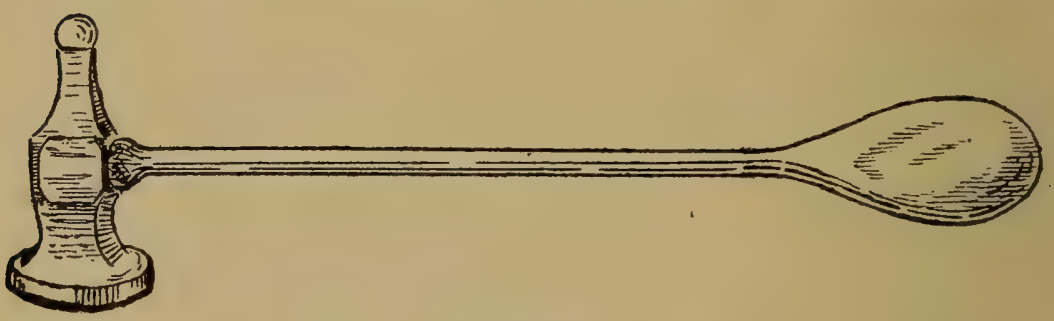

FIG. I. REPOUSSÉ HAMMER.

flat, circular face. The handle is very thin and flexible, and is usually made of lancewood, made much bigger at the end to allow of a firm grip.

For heavy work it will be advisable to have an ordinary carpenter's hammer, techni- 


\section{TOOLS USED IN METALWORK 5}

cally known as a "Warrington" pattern (Fig. 2).

Mallet (Fig. 3). This is a tool which comes into use probably more than any

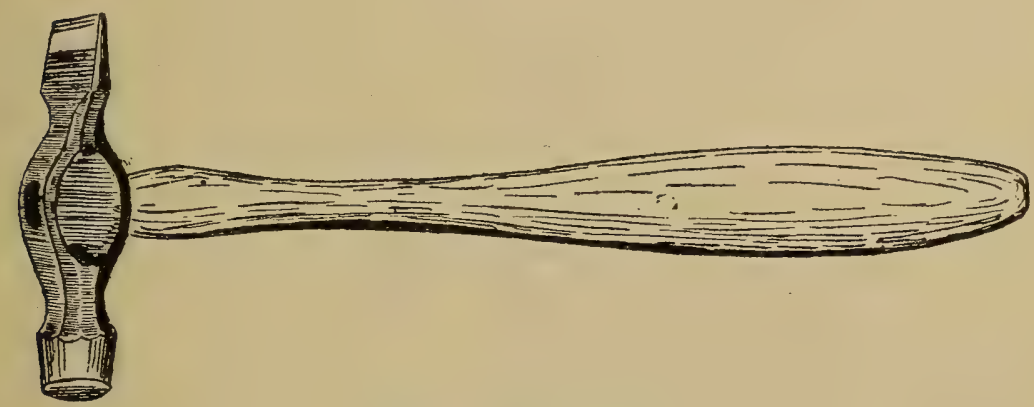

FIG. 2. HAMMER.

other, and is quite unlike any other make of mallet. The head is of boxwood, with small

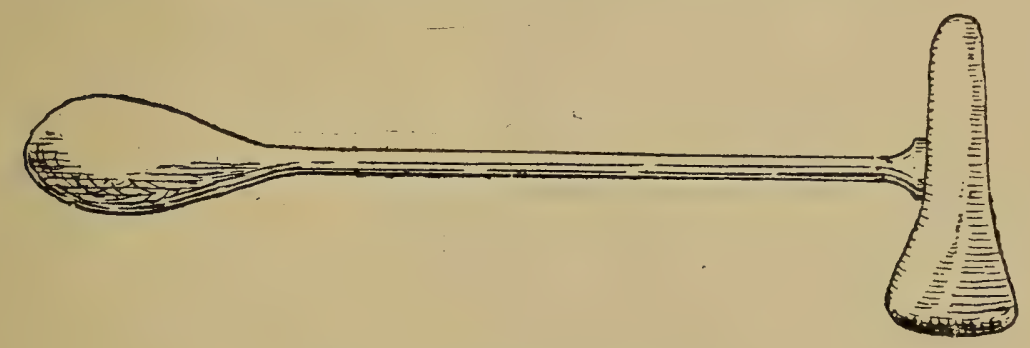

FIG. 3. REPOUSSÉ MALLET.

and large circular faces, slightly rounded. The handle is usually of lance-wood, and of the same shape as the hammer handle. 
Tracer (Fig. 4). This tool is made from cast-steel, very highly tempered, and is ground to a thin edge on two sides, similar to the edge of a screwdriver. It is made

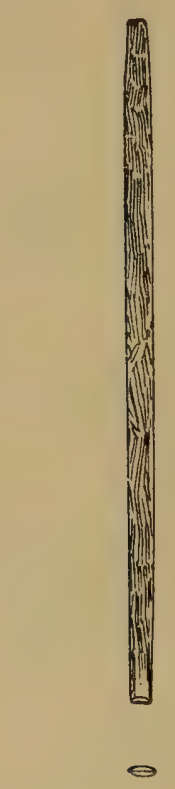

FIG. 4. TRACER.

in several sizes, the medium size being the most useful. They may easily be made by the careful worker from $\frac{1}{8}$ th bar steel, ground on a grindstone or emery-wheel and then tempered. 


\section{TOOLS USED IN METALWORK 7}

Raising tools (Steel) (Fig. 5). About six or eight of these useful tools, in assorted sizes, will be needed at first, and the stock increased as required. These are made of

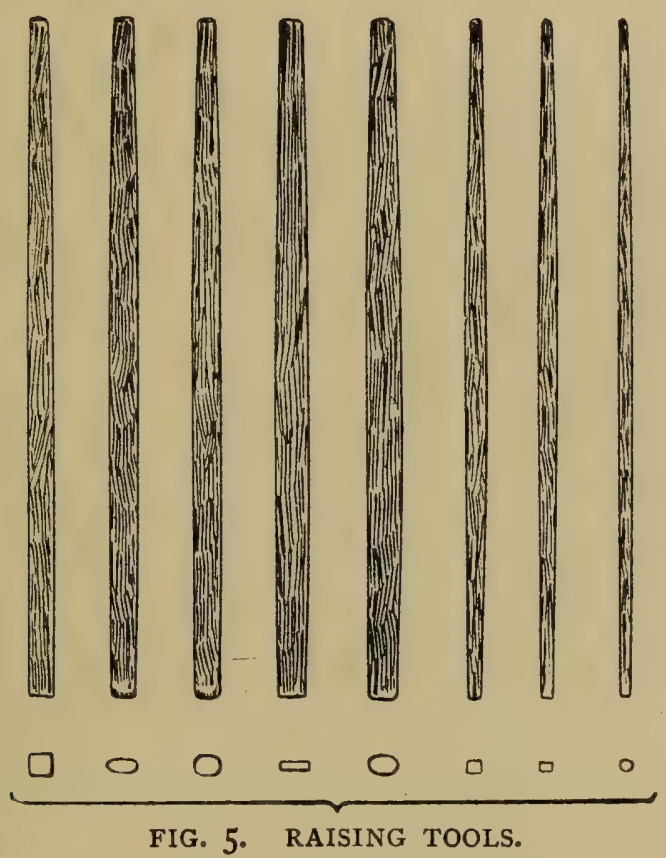

cast steel, highly tempered and burnished, and must stand hard wear. They are made from various-sized round and square steel bar, ground to shape on an emery-wheel, thoroughly hardened and tempered, and then polished on a buff-wheel to a fine finish. 
Raising Tools (Brass) (Fig. 6). Brass of a very hard quality is used to make the larger sizes of raising tools. They are extremely useful, for they do not bruise the surface

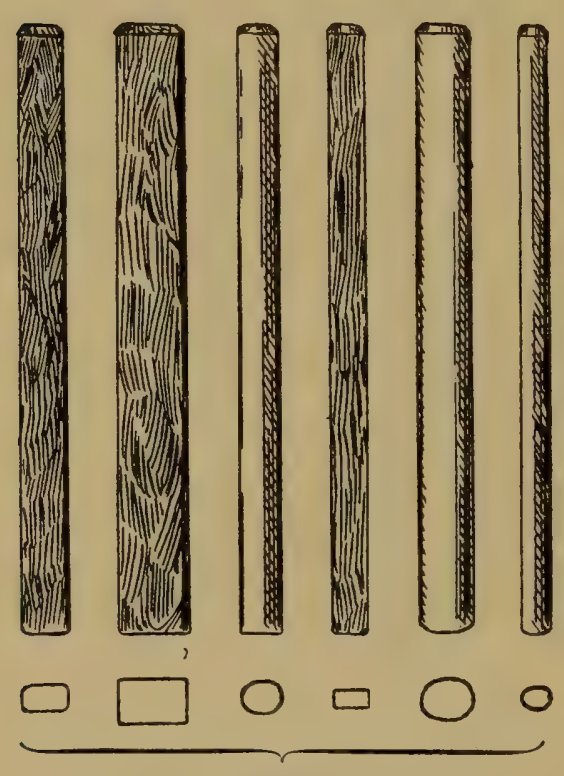

FIG. 6. RAISING TOOLS.

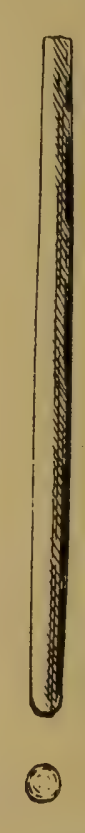

FIG. 7. PEARLS.

of the metal as a harder steel tool would. Only the larger sizes are needed, the smaller ones being too soft for ordinary use.

Pearls (Fig. 7). These are really a type of steel raising tool, but are all circular at 


\section{TOOLS USED IN METALWORK 9}

the point, varying only in size. A small selection only, will be needed.

Punches (Fig. 8). A large variety of punches are made, but the Repoussé worker

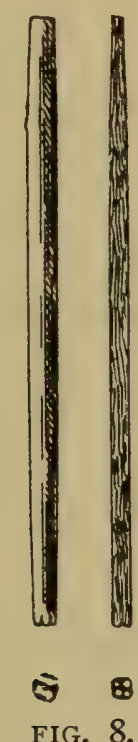

REPOUSSÉ PUNCHES.
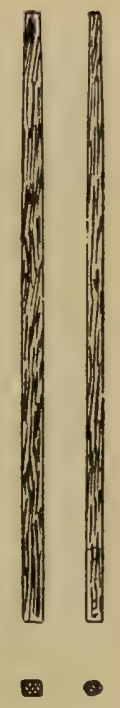

FIG. 9.

MATTING TOOLS.

need only trouble himself with one kind for a start, and two sizes will be needed-a large and small "three point." Other styles are circles, square pyramids, stars, crosses, etc.

Matting Tools (Fig. 9). Here, again, a large number of different shapes may be 


\section{REPOUSSÉ METALWORK}

had, but two or three only will be needed, the oblong and elliptical shapes being most useful. Punches and matts are used to break up the plain surface of the metal, and are sometimes termed grounding tools. They give a texture to the surface as a relief or "set-off" to the raising.

FIG. IO. SCRIBING POINT.

Scribing Point (Fig. Io). A hardened piece of steel with a blunt and a sharp end, used in scratching in the traced lines on the metal. They should not be smooth, but made of twisted bar to afford a firm hold.

Steel Rule. This should be about 12 in. long, and is used in measuring up the metal and in drawing straight lines with the scriber. The pressure exerted in ruling a line with the scriber would soon wear a wooden rule out. 


\section{TOOLS USED IN METALWORK 11}

\section{Wing Compasses (Fig. I I). For marking}

curved lines on the metal, also useful as callipers in gauging distances.

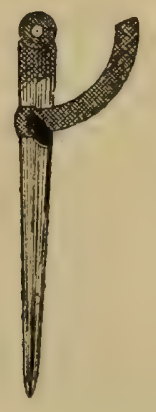

FIG. II. PAIR_OF COMPASSES.

Burnishers (Figs. I 2 and I $2 a$ ). Made of highly polished and tempered steel.

FIG. I2. BURNISHER.

FIG. I2a. BURNISHER.

Pincers (Fig. 13). A pair of ordinary pincers will be needed for holding the metal whilst heating, etc. 
FIG. 13. PINCERS.

Pliers (Fig. I4). A pair of round-nose pliers will be found very useful for turning

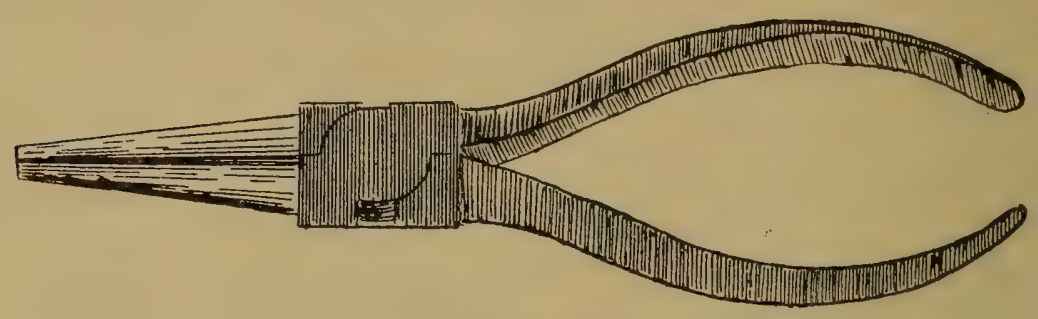

FIG. I4. ROUND-NOSED PLIERS.

the edges of the metal and bending to any required shape.

Steel Square (Fig. I 5). A 6 in. or 8 in. square will be needed to true up edges of work and mark off lines at right angles to edge.

Shears (Fig. I6). A pair of medium-sized metal cutting shears will be required. They should have a blade about $2 \frac{1}{2}$ in. long and should open easily. 


\section{TOOLS USED IN METALWORK 13}

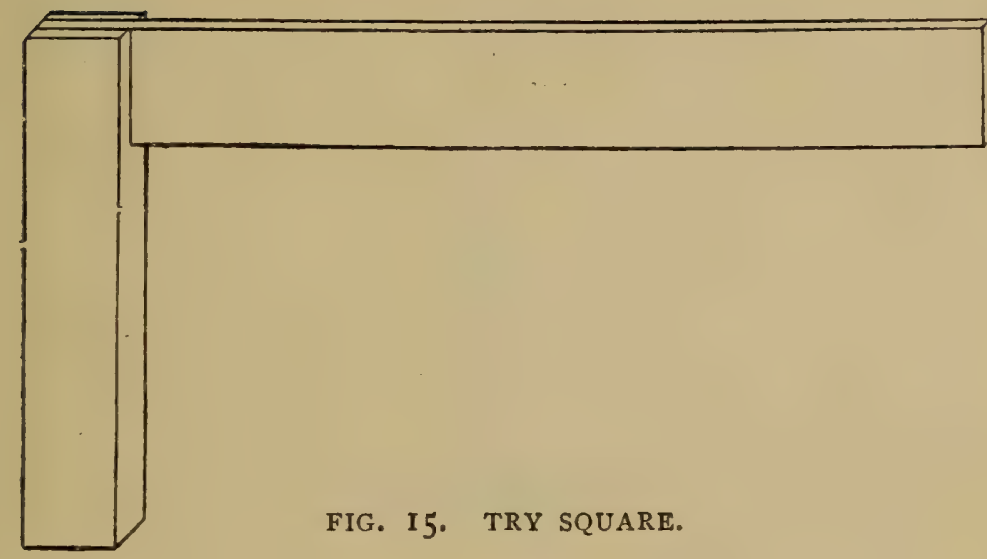

Files. A small assortment of flat safeedge pillar files and small rounds, all fine in texture, should be provided.

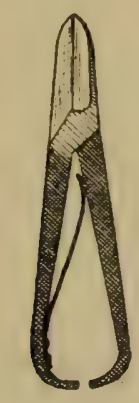

FIG. I6. SHEARS.

$A$ Spatula or old knife to level the surface of the pitch block after the work has been taken off. 
A Small Drill (Fig. I 7) will be found very useful, but may be dispensed with for very small holes, a punch doing all that is

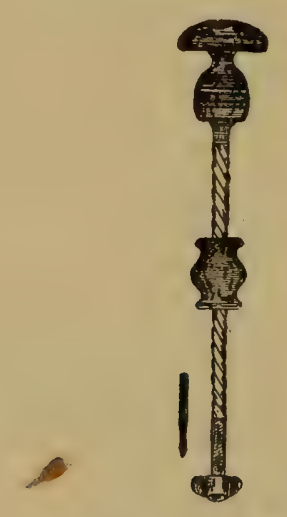

FIG. I7. DRILL.

necessary in any of the models in this course. The rough edge left by the punch should be filed smooth.

$A$ Tinman's Stake (Fig. I8) for shaping up work will be required.

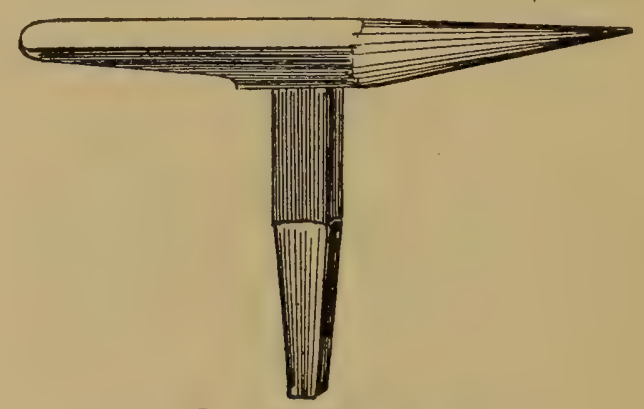

FIG, I8. STAKE, OR ANVIL. 
A Table. For class work a table similar to that shown in Fig. I 9 will be found very

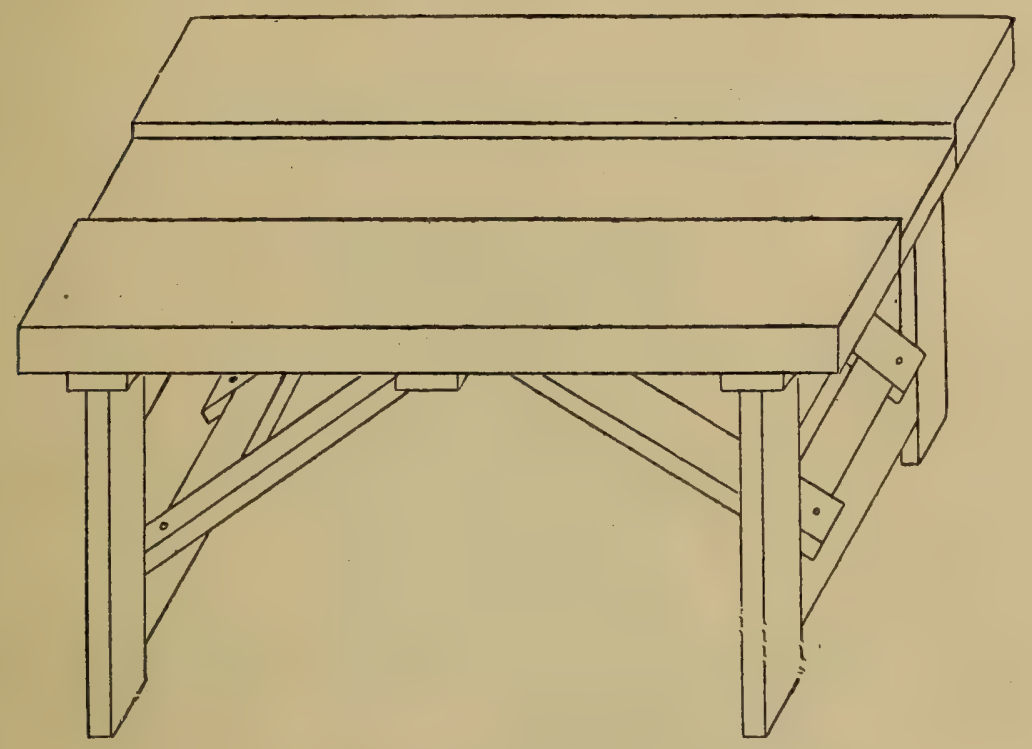

FIG. I9.

useful. It is strong and yet portable, and should be big enough to sit three students each side.

\section{DRAWING INSTRUMENTS}

Boxwood ruler I 2 in., $45^{\circ}$ and $60^{\circ}$ setsquares, pair of pencil compasses, pencil H.B. and drawing pins, also a stock of drawing paper, tracing and carbon papers. 


\section{APPLIANCES AND MATERIALS}

A Blow Lamp (Fig. 20) or Blow-pipe and Bellows. Of the former kind of heating apparatus two styles recommend themselves

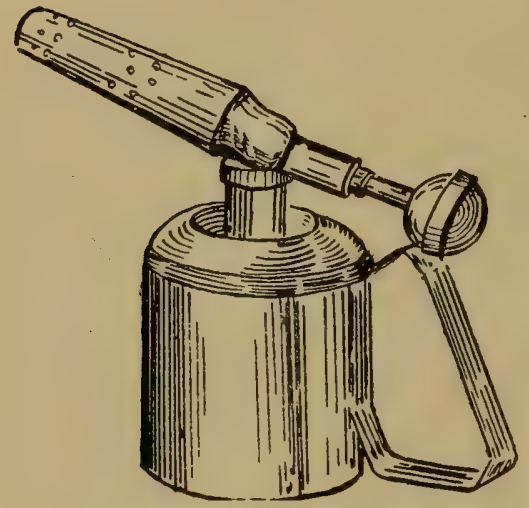

FIG. 20. BENZOLINE LAMP.

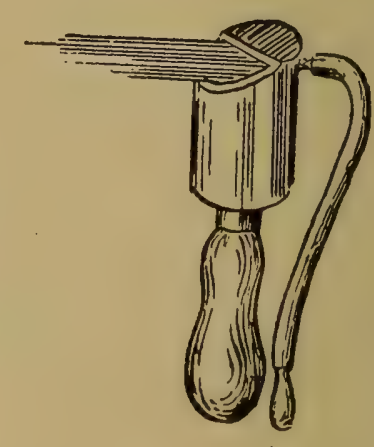

FIG. 21. BLOW FLAME.

- the simple methylated flame blown by the breath, called the Garrett lamp (Fig. 2I), or the "Roarer" benzoline lamp (Fig. 20), not so simple in construction, but automatic in use. 
With care the benzoline lamp is quite safe and very useful where gas is not laid on, but wherever possible the blowpipe and bellows should certainly be used, a much larger and

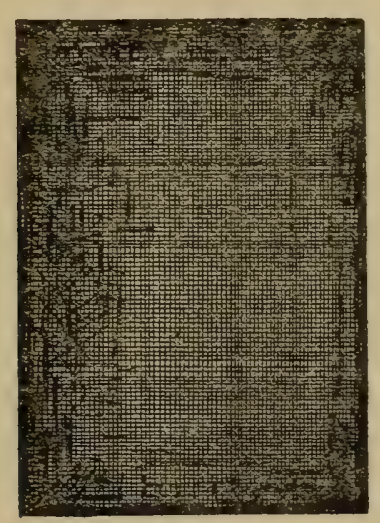

FIG. 22. LEATHER OR CANVAS SANDBAG.

more powerful flame being available, and without any risk of explosion.

$A$ Block of Elm about $\mathrm{I} 2$ in. square and 3 or 4 in. thick, with a true face, will be needed for flattening purposes.

$A$ Canvas Bag (Fig. 22) filled with fine silver sand to about three-quarters of its capacity. This will be in great demand to 


\section{REPOUSSÉ ME'TALWORK}

rest the metal on while beating out large surfaces. Size of bag, I 5 in. by I 2 in.

Small Blocks of very hard wood, such as lignum vitæ, will be required for turning up edges of trays, etc. The blocks should vary from 2 in. to 4 in. square.

$A$ Small Vice is very useful, but may be dispensed with for a start.

Polishing Brushes. A nail-brush and platebrush are most useful, the former for rough cleaning, and the latter for final polishing.

Copper and Brass about 7 or 8 metal gauge and fairly soft. The best quality should be obtained, if not, much work will be spoilt owing to defects and blemishes in the surface.

A Metal Frame Saw is a useful addition to the stock, and is needed further on in the course. A frame with an adjustable handle is most convenient; the broken saw-blades may then be used up. The latter should be fairly fine and thoroughly well tempered. 
Pumice Powder for cleaning and polishing purposes will be required. It may be used over and over again.

Emery Cloth of $\mathrm{F}$ degree is needed for first of all cleaning up and giving a grained surface to the metal.

Sweet Oil. This will be needed in conjunction with the emery cloth in cleaning.

Turpentine. A small quantity should be kept and a rag moistened in it to remove grease.

Lacquer. This should be Best Colourless, and is applied with a camel-hair brush while the metal is hot.

The Composition. This is an important material, and may be purchased made up or easily made by the worker himself. It is much cheaper to make it from one of the following recipes :-

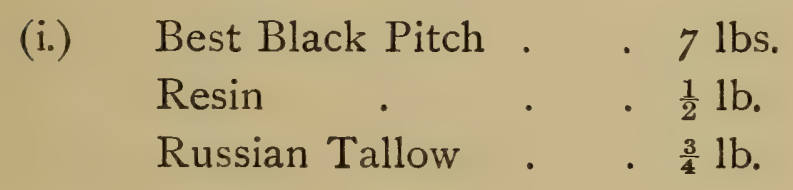


These ingredients should be slowly melted in a large iron saucepan or pot and well stirred until thoroughly mixed. On no account should the pitch be allowed to boil. Add Plaster of Paris . . Io lbs.

slowly, stirring continually until the whole is mixed, then pour into a shallow box about I 4 in. by 12 in., and about $\frac{3}{4}$ in. deep.

The above quantity is sufficient for about four blocks, and if less is required it should be divided in right proportions.

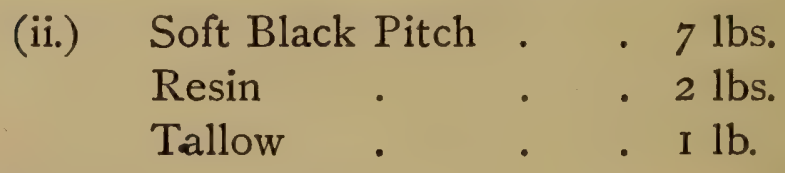

When melted add

Bath Brick powdered . 7 lbs.

This is made in exactly the same way, and if anything is cleaner than No r. in use.

(iii.) $\begin{aligned} & \text { Soft Black } \\ & \text { Resin . } \\ & \text { Tallow . }\end{aligned}$
When melted add

Hot White Sand . . 8 lbs. 
APPLIANCES AND MATERIALS 21

Tallow has a softening effect on the cement, while Resin makes it harder. It is advisable to have two blocks-one composed of fairly hard composition, and another of softer cement, the latter being most suitable for working up high relief, and the former better for tracing and finishing on.

FIG. 23. PITCH LADLE.

For small work many Repoussé workers use a bowl of pitch, so that it may easily be turned, but this is only necessary for intricate work.

Special Cement, costing about is. or less per pound, which only requires melting, is sold by dealers in Repoussé tools. It is very clean and most suitable for those who do not care for the trouble of mixing it themselves. 
Pitch Pot and Ladle (Fig. 23) for mixing up composition. An old saucepan would make an excellent pot.

Pitch Block (Fig. 24), made of yellow deal, a base 14 in. by 12 in. and $\frac{5}{8}$ thick, surrounded by a rim of $\frac{3}{8}$ wood $I \frac{1}{4}$ wide.

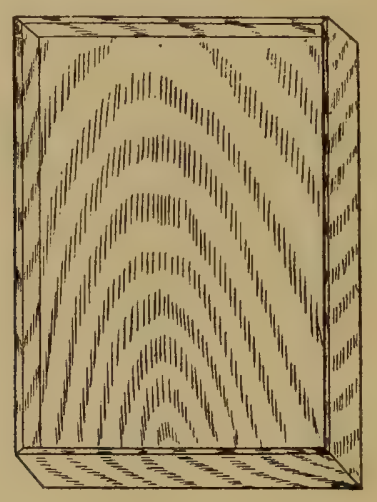

FIG. 24. TRAX FOR PITCH. 


\section{METAL SUI'TABLE FOR REPOUSSÉ}

THE most suitable metals, and also the most commonly used, are Copper and Brass.

Silver is admirably adapted, but is generally too expensive for the amateur.

Gold is probably the finest metal for the Repoussé worker, but its cost renders it only suitable for expert goldsmiths.

Aluminium is quite suitable, but is rather brittle.

Wrought Iron in very thin sheets is sometimes used, and good effects are often gained by its use.

Soft Steel, too, may be worked, and under the expert worker produces some beautiful effects.

Copper. This metal either in a pure state 


\section{REPOUSSÉ METALWORK}

or as ore is found in several parts of the United Kingdom and other countries. It is smelted and all impurities removed in the course of much heating, and is finally run into blocks.

It is then refined by heat and toughened, and when of the right colour is run into moulds and rolled into sheets, being frequently annealed during the process.

To render it quite soft and ductile it must be annealed. This is done by heating to a dull red heat and cooling, either by placing in ashes or plunging into cold water; the latter being rather risky in the case of raised metal, for the sudden cooling is apt to crack the thin edges of the worked parts.

Brass. This is composed generally of two parts of Copper to one part of Zinc. If $\mathrm{Zinc}$ is added in greater proportion to this the Brass becomes both harder and brittle. In manufacturing Brass, the Copper is heated in crucibles to a liquid state and 
the Zinc gradually added and stirred until all is melted, then it is poured into moulds, and when cold rolled in the same way as Copper.

Silver. For those workers who may have a liking for working in this pleasant metal the following hints will be useful :-

Silver will bear a considerable amount of raising, and may be used much thinner than either Copper or Brass.

Sheet Silver when purchased is hard and springy, and before it can be used must be thoroughly annealed. The marks on the surface should be removed while the metal is quite flat, and the best way of doing this is to thoroughly rub the surface with Water of Ayr stone. A brilliant surface should be given first, or else much difficulty will be experienced in finishing off when the work is completed.

For a little extra the dealers in Repoussé materials will always provide silver annealed and planished ready for immediate use. 


\section{EXERCISE I}

\section{A SQUARE MAT}

THIS exercise provides a useful article and serves as an introduction to the first stages of metalwork. Quite as much care should be taken with it as with a more difficult piece of work, so that the result will prove a good exercise and the difficult operation of tracing satisfactorily overcome.

Drawing. The model must first be considered and drawn out full size on a piece of drawing paper. Great care should be taken that the lines are at right angles to one another, or the whole effect will be spoilt.

Metalwork. First cut out from a sheet of brass a piece just a little larger than the size given; not more than $\frac{1}{4}$ in. The action 


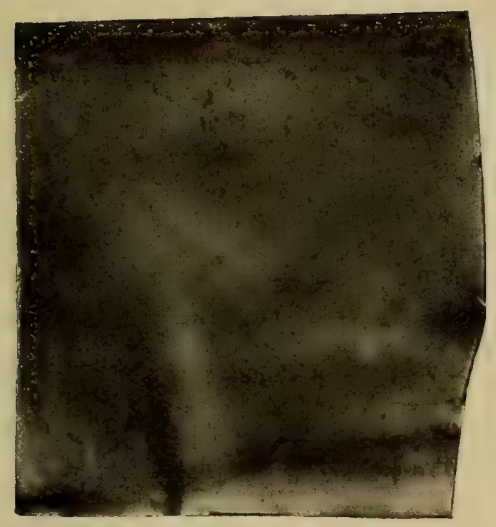

FIRST STAGE OF EX. I

PIECE OF METAL CUT OUT FOR CLEANING AND STRAIGHTENING

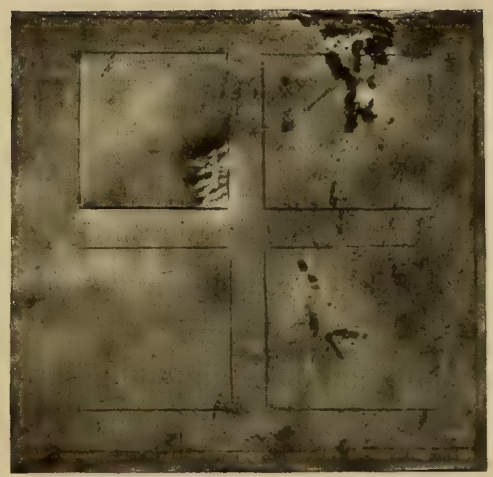

SECOND STAGE OF EX. I LINES TRACED AND GROUND REAIYY FOR PUNCHING

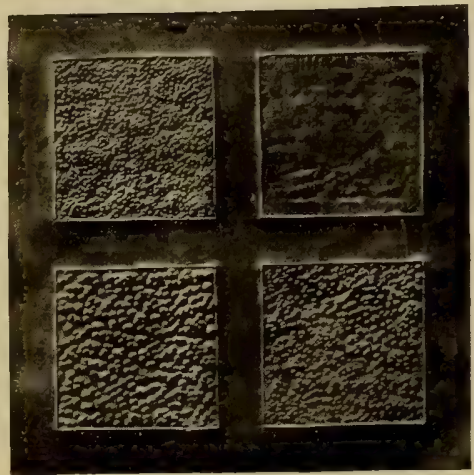

FINAL STAGE OF EX. I METAL CUT TO SHAYE, POLISHED AND LACQUERED
GIROUND PUNCHED AND METAL READY FOR LEVELLING AND TRIMMING UP 

of the shears often results in the cut piece being bent, so that before proceeding further it must be straightened out. This is done

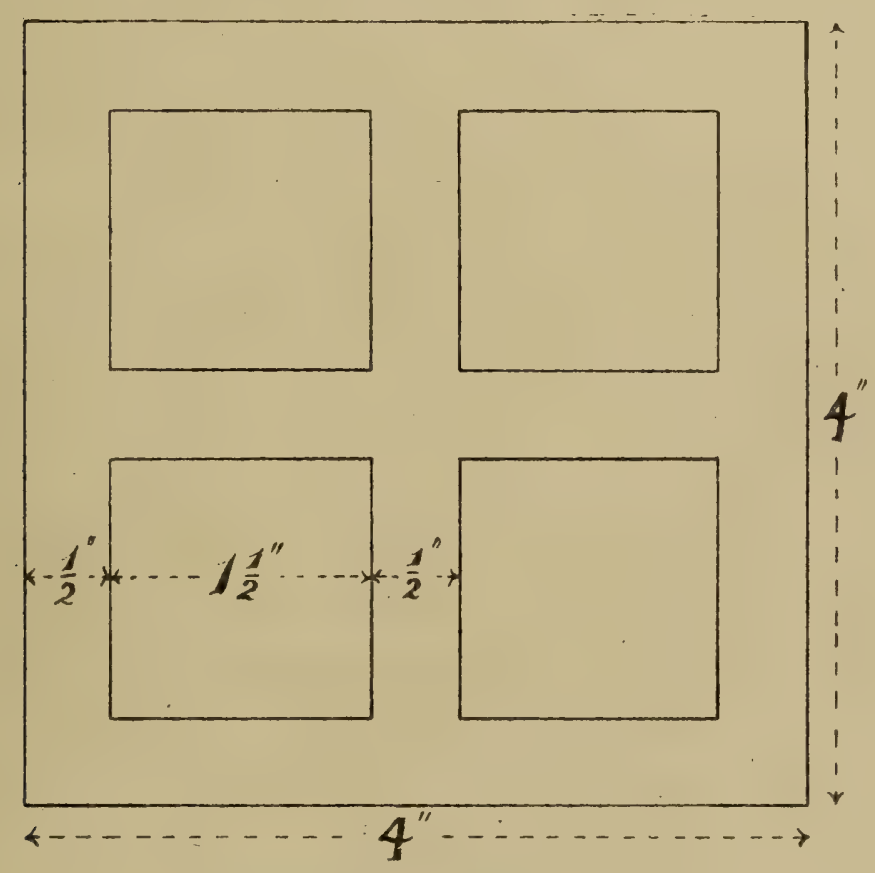

EXERCISE I. A SQUARE MAT.

with the large face of the mallet, on a block of wood, and with light "springy" blows, until all the dents and uneven edges have been straightened. Heavy blows with the mallet will only mean more dents, so it is 
most important that the levelling should be lightly done.

Both sides must now be cleaned with $F$ emery cloth and oil, using a few drops of the latter to prevent scratching. Wipe off all trace of oil when clean, with a rag or piece of waste moistened with turpentine.

The next step is to make a tracing, on tracing paper, from the drawing. Then place the metal, best side uppermost on the table, and secure the tracing by means of two drawing pins. These should be placed close to the two top corners of the metal. Next place a piece of carbon paper under the tracing and go over the lines, either with a pencil or the blunt end of the scriber. The lines of the drawing will now be traced on to the metal, but as these carbon marks are easily erased, the sharp point of the scriber should be brought into use, guid. ing it against a steel rule and so scratching in the lines. The carbon marks may now be rubbed off with the turps rag. 


\section{A SQUARE MAT}

Another important stage of the work is now reached, i.e. fixing the metal on the pitch block. It would be quite possible to do the whole of the work without fixing it on pitch-by nailing it down on a piece of hard wood, covered with lead-but this is not as satisfactory as the former method, and only suitable for flat chasing.

Take the pitch block and heat the surface until about twice the area of the plate is melted, to a depth of $\frac{1}{4}$ in. To do this one of the methods of heating mentioned above must be used, the melting being very cautiously done to avoid overheating, and consequently blistering, the pitch. When the pitch is melted, warm the piece of metal and place it in the centre of the melted portion, press on it slightly, and when firmly laid, push the ridge of pitch a little way over the edges (Fig. 25). The fingers must be kept wet while this is being done, or the hot pitch will stick to them and cause a nasty burn. 
The block should now be put on one side, quite level, until cool. The first tool opera-

FIG. 25.

SECTION THROUGH PITCH BLOCK, WITH FIXED METAL.

tion is now commenced. Take the tracer and hammer, and placing the pitch block

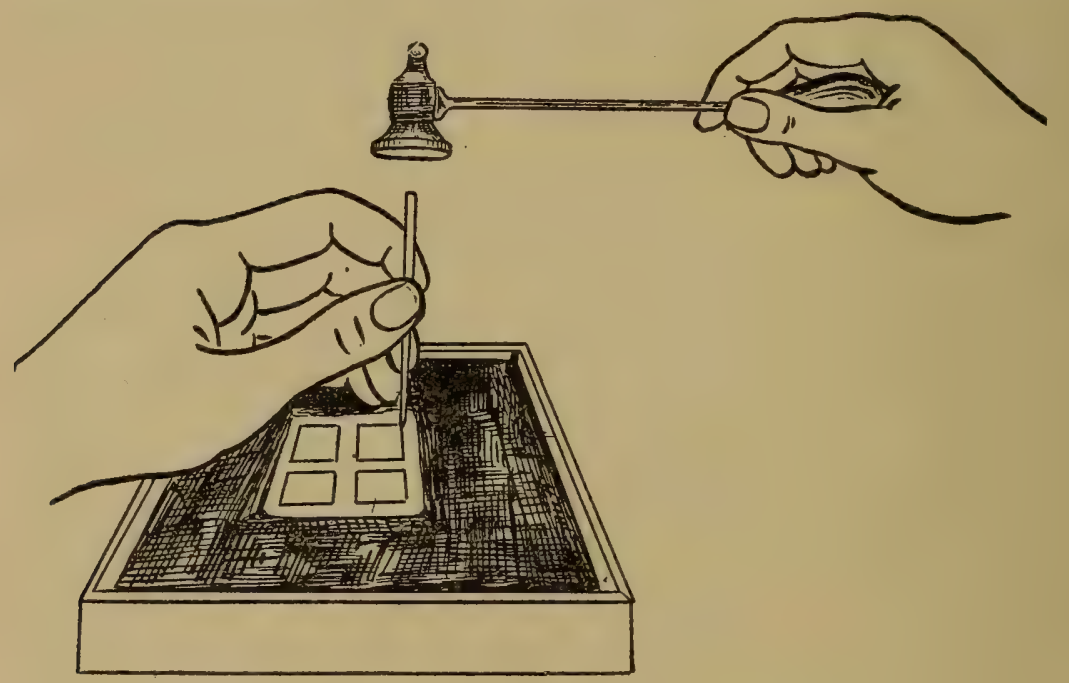

FIG. 26.

METHOD OF HOLDING TRACER AND HAMMER.

near a good light, preferably coming from behind the right shoulder, hold the tools as shown in the illustration (Fig. 26). 
The object of the tracer is to indent the scratched line in order that it may show on the reverse side of the metal (Fig. 27). It is an operation requiring great care and much practice before facility can be acquired. The action of the tracer under the continuous blows of the hammer is difficult to explain,
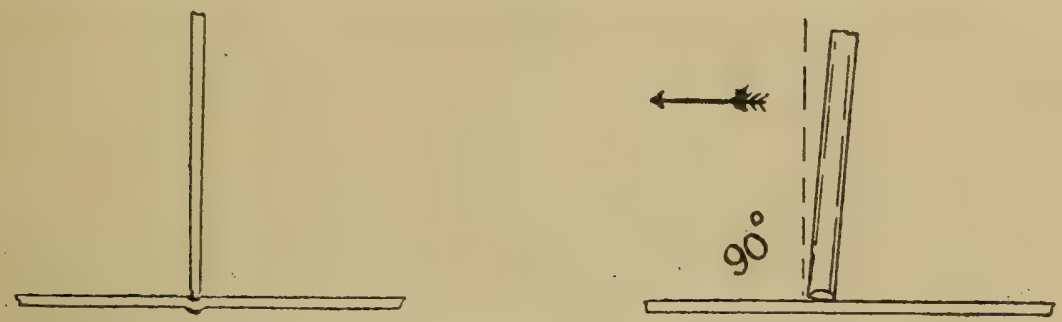

FIG. 27. METHOD - OF USING TRACER.

but it should be remembered that each blow of the hammer sends the tracer into the metal, and the resiliency of both metal and pitch causes the tool to rebound and work itself slightly forward. It is this action continued which forms the line. The tracer should not be held tightly, for if grasped firmly would soon cause cramp in the fingers. Watch closely that the tool is only slightly 
out of the perpendicular, leaning away from the worker (Fig. 27). With a light touch, keep the tracer to the line, gradually working toward you until the whole of the scratched line becomes one continuous dent. If the above method is not carefully followed the result will be a series of uneven marks having a very poor appearance (Fig. 28).

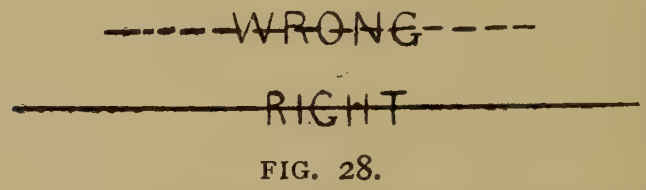

CORRECT AND INCORRECT METHODS OF TRACING A LINE,

All the lines should be traced with the block in the same position, practice thus being gained in holding tracer various ways, and then the squares filled in with grounding or matting marks, and here practice will be gained in two different tools. Two opposite squares should be grounded with a "mat" which will just dull the bright surface, the other spaces filled in with a three-point 
punch, making a groundwork of small round indentations. Care should be taken that the marks do not go over the traced lines, but are worked up neatly to them. The hammerblows in this case as well as in tracing should be light, the handle lightly resting in the palm of the hand.

When the grounding is finished, the next step is to take the metal off the pitch. This is easily done by "prizing" the overlapping cement with an old knife or chisel, and with a little gentle persuasion the metal will soon leave the composition. This method will not do if the pitch is warm, and in such a case the flame of the lamp or blow-pipe should be played over the metal, and one corner lifted up and pulled with the pincers. Very little heat will suffice.

To remove any pitch remaining on the metal, it should be slightly warmed and rubbed over with a piece of waste, taking great care not to overheat it, for too much 


\section{REPOUSSÉ METALWORK}

heat will burn the pitch and discolour the metal, rendering the cleaning up again a very difficult task.

Now cut off the surplus metal with the shears, and file along the cut edge to remove the "arris," and then straighten it carefully on the hard block. To finish the exercise the metal must be well polished with pumice powder, this being vigorously rubbed all over the surface with a hard nailbrush. A bright polish will gradually result, and the work in the first exercise will be completed. 


\section{EXERCISE II}

\section{A SQUARE TRAY}

A GLANCE at the illustration of this exercise will show where this model differs from the previous piece of work, in point of difficulty. The traced lines are not only longer, but some of them are curved, and in bending the edges a new operation is introduced.

Drawing. There is nothing difficult here, a pair of compasses being used to make the curved lines.

Metalwork. To give a change from the last exercise it will be better to use copper, a piece about $\frac{1}{2}$ in. each way larger than the drawing, being cut out. Carefully straighten and clean it, taking off the oil with the turps rag as in the case of the first exercise. Fix on the tracing and carbon papers, transfer 
the design, and scratch it in with scriber. Rule the straight lines, and use the wing compasses for the curves.

Now mount the metal on the block, and, when ready, go over the straight lines with the tracer. This should be done with ease ; the only difficulty will be found in the tracing in of the curves. It will be well to bear in mind that trying to force the tracer along is useless. It must be held lightly, and quite as lightly guided along the curves, which for a start are only very simple.

When the tracing is finished the surface, or ground, should be matted or punched; the actual tool used may be left to the choice of the worker, so many effects may be made by the various matts and punches.

A too mechanical appearance should be avoided, and, except in a few instances, a regularity of grounding marks is inartistic.

The object of grounding is merely to break up the surface of the metal and bring 
out the lines of the design. A deliberate placing of the grounding marks in a regular

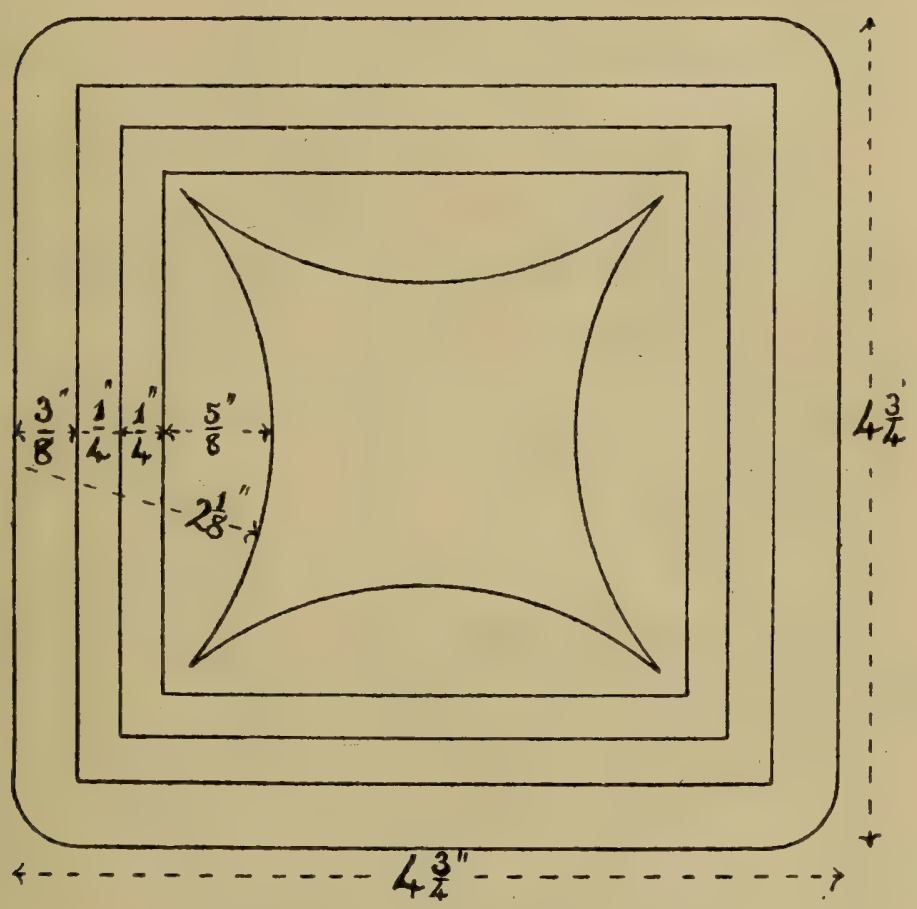

EXERCISE 2. A PIN TRAY.

pattern will probably have the effect of spoiling an otherwise good design.

When this part of the work is finished, take the metal off, clean it, and cut off the surplus with the shears, filing up the edges 
smooth and true, with the corners rounded as shown. Now polish up both sides, and if desired burnish up the bright parts, securing the metal by means of tacks, and with a lubricant of soapy water rub carefully over each part with the burnisher.

The bright effect thus gained is caused by closing up all the pores and minute scratches on the surface, and making it perfectly smooth.

To bend up the edges, a small block of lignum vitæ about the same size as the base of the tray is required. Place the metal face downwards on the block, so that the line where the bend commences is on the edge of the block. A few taps with the mallet will be all that is necessary to bend the side. Treat each side in this manner. Now attend to the corners, for these will require some careful adjusting with the small end of the mallet, and perhaps touching up with the round-nose pliers, to get a good finish. 


\section{A SQUARE TRAY}

Polish up again to remove any trace of grease, and when slightly warmed, not too hot to hold, paint over a coating of lacquer to preserve the polish and prevent oxidisation. In lacquering care must be taken that the lacquer is laid on evenly, and no spaces are left untouched, or they will soon tarnish. 


\section{EXERCISE III}

\section{AN OCTAGONAL TRAY}

THIS exercise contains more practice in curved tracing and increased difficulty in bending the edge.

Drawing. This is simple, the design being made up in a square.

Metalwork. Start with a piece of brass a little larger than finished size, thoroughly flatten and clean it up and trace on design, using compasses and scribing point in scratching the lines. Now mount the metal, and when ready for work, trace in the lines very carefully. It will be found advisable, after tracing the square lines, to do the small centre pattern before the two circles are attempted, for as this is the most difficult 


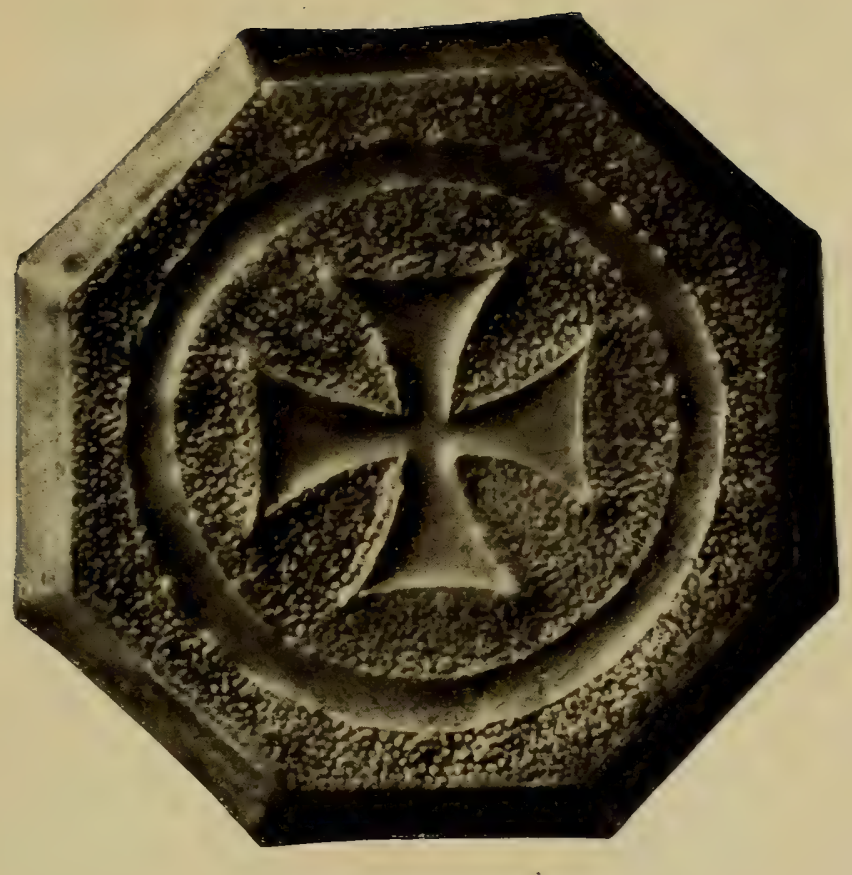

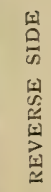

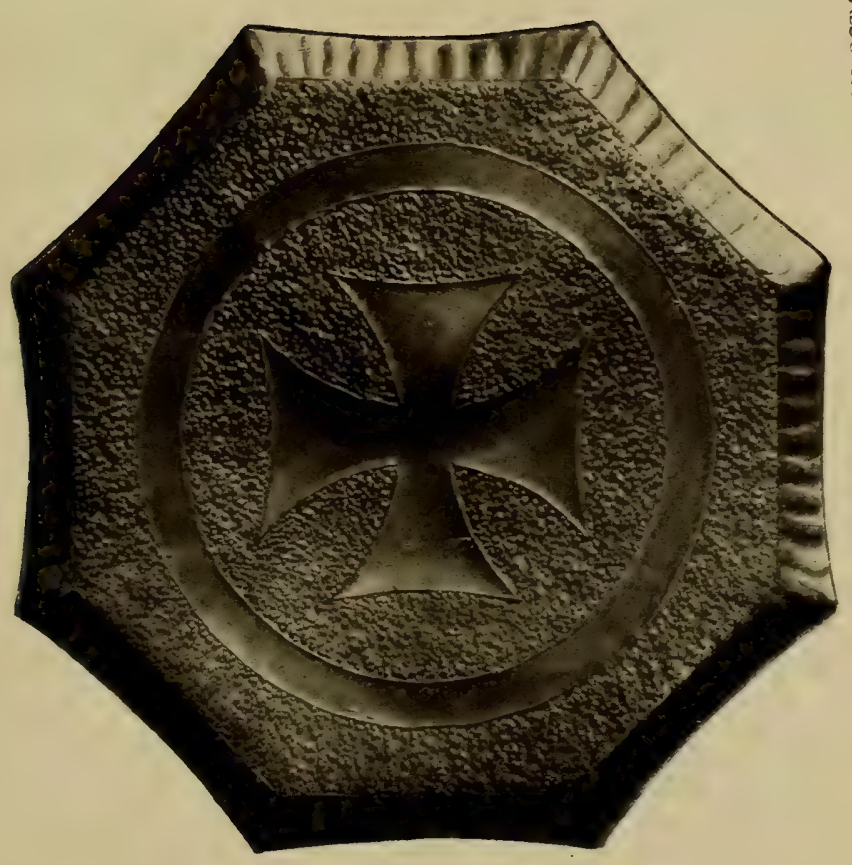

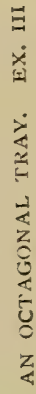

है 

part, the practice gained in the smaller curves will get the hand in form for the harder work.

The next step is to choose the grounding punch and put in the ground, and then the

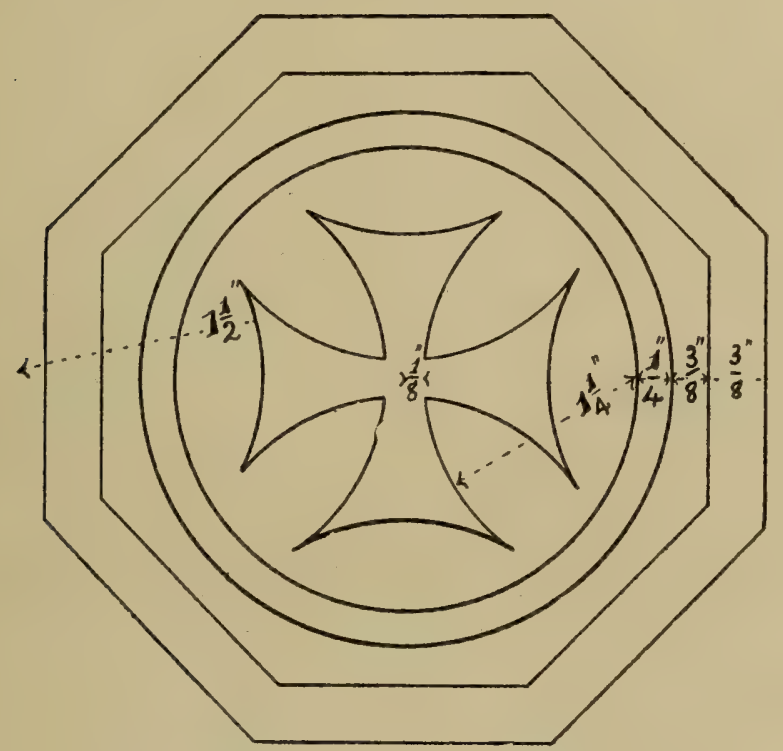

EXERCISE 3. AN OCTAGONAL TRAY.

work on the block is finished. Remove the metal; warm it and clean off the pitch, and with shears and file cut it to shape. If a burnished surface is required, it should be done at this stage. Now the edges must be 
42 REPOUSSÉ METALWORK

gradually bent, great care being exercised in working the bevelled corners. A good polishing with pumice powder and a coat of lacquer will complete the model. 


\section{EXERCISE IV}

\section{A FINGER PLATE}

A NEw operation, that of raising on a sandbag, is introduced in this exercise.

Drawing. The side view is necessary to show the amount to be raised or beaten up. Metalwork. Cut out a piece of copper, somewhat larger than the size marked on the drawing, but before cleaning it should be annealed. The previous exercises have not required this treatment, because, as all the work has been done on one side only, any extra softening of the metal was not really required; but in this case, the beating with the mallet (which has the effect of "thinning out" and hardening the metal) can only be satisfactorily done when the metal is in a tractable state. 
The process of annealing is not difficult ; hold the metal by means of pincers, and play the flame all over it, until it is heated to a dull red, then either let it slowly cool or put it in water at once. Many metalworkers advocate the former method, but for

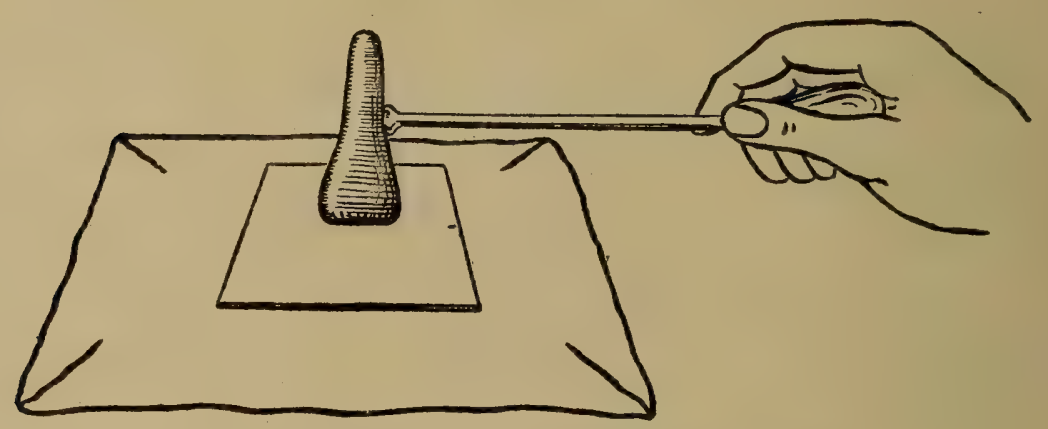

FIG. 29. METHOD OF USING SANDBAG.

ordinary purposes, the same effect is gained if the cooling is quickly done, and much time is saved.

The next step is, of course, flattening and cleaning, which should be done quite as carefully as hitherto, and when the design has been traced and scratched on, mount it on the block and trace the inner line only, 

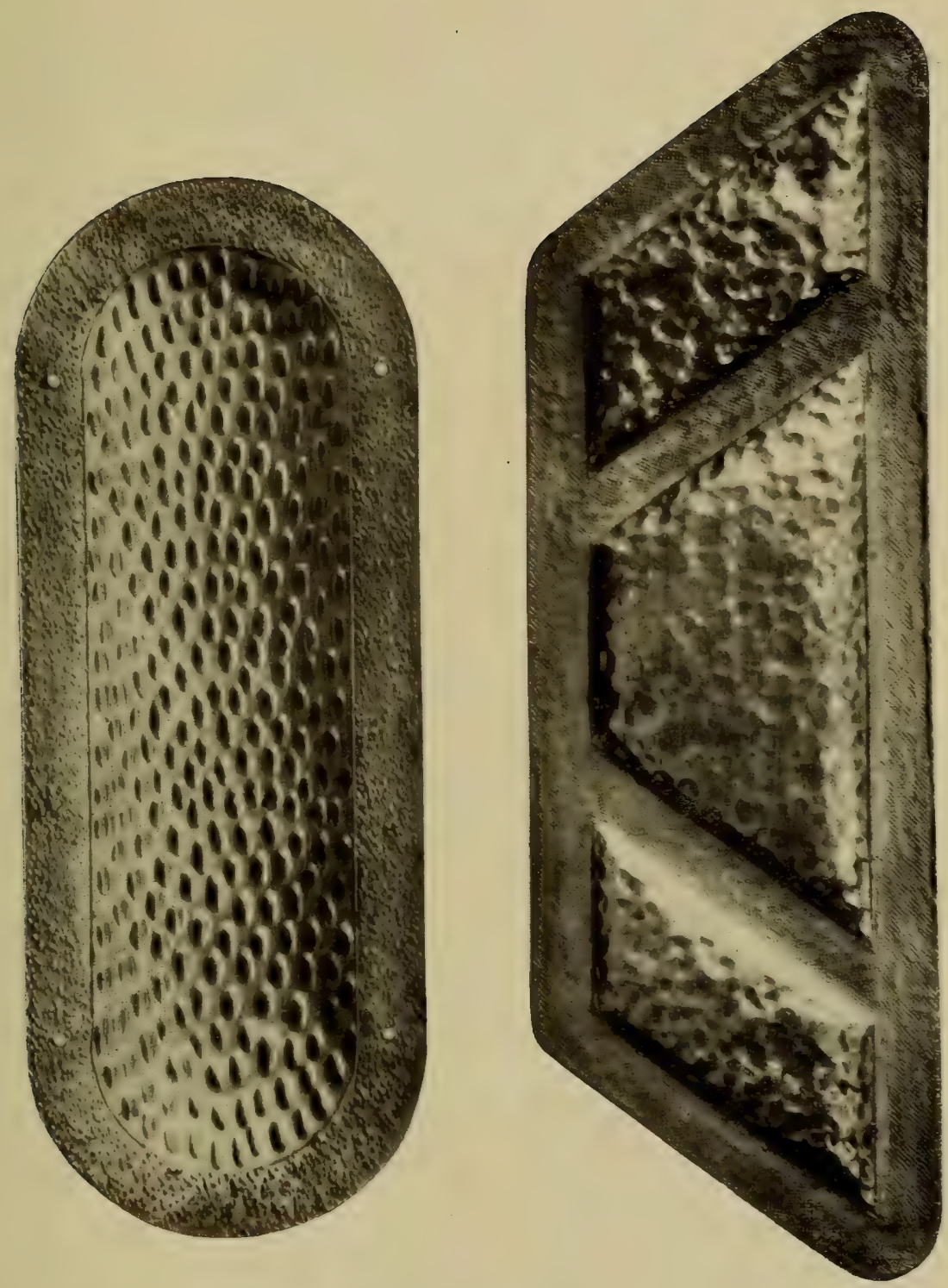

A SIMPLE FINGER-PLATE 



\section{A FINGER PLATE}

the outer one being merely a guide to cut to shape by afterwards. When the tracing is finished, take the metal off and warm it to remove the surplus pitch, and then take a sandbag and mallet and proceed in the

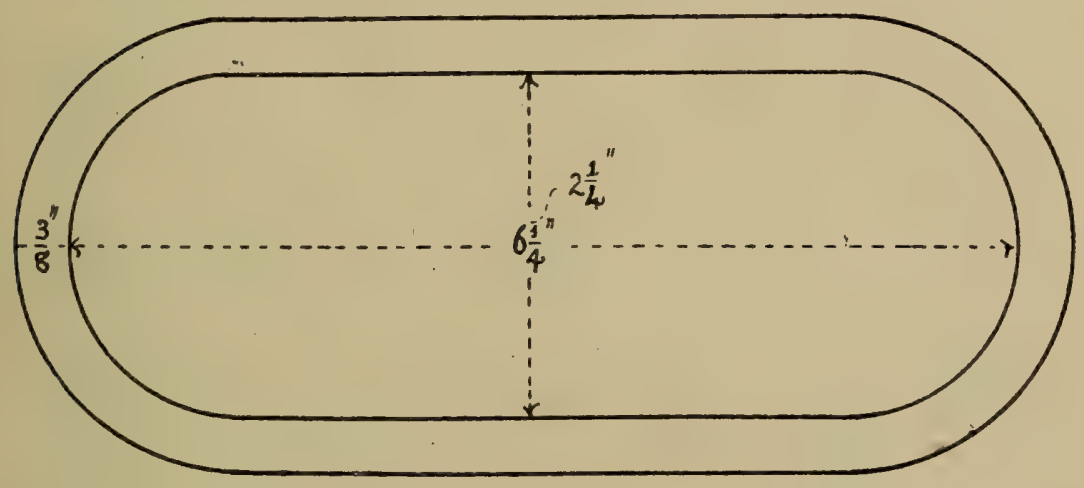

EXERCISE 4. A FINGER PLATE.

following manner to beat out the recess. Level the bag and place the metal upon it, upside down, and it will be seen that the traced line shows through (this is the real use of the tracer). Now, with the large end of the mallet, give a series of firm blows, starting in the middle, accurately directed 
within the traced space, and gradually worked towards each end. It will be found that the edges will cockle up and get twisted during the process, so before another series of blows is given, the work must be straightened out, first of all placing the metal face upwards on the block, and hitting the edges level with the smaller face of the mallet, and then turning the metal over, place it on the edge of the block, and gradually work to the traced line. This process of sandbag raising and subsequent straightening must be repeated until the whole space is raised to the required size and quite even.

Now take some small pieces of pitch from the block and fill in the hollow, slowly melt this, taking great care it is thoroughly melted and there are no air bubbles. Place it on one side to cool, and when the surface of the block is melted, mount the exercise face up and bank up the pitch well around 
the edge. When cool a large round raising tool or pearl should be used to punch the raised surface, and if desired a small matt or punch may be used on the edge, but this is a matter of taste. Clean up, trim and lacquer as before, to finish the exercise. 


\section{EXERCISE V}

\section{A ROUND TRAY}

THIs is another example of sandbag work, but in addition a start is made with raising tools, used on the block.

Drawing. This shows front and side views.

Metalwork. Copper will be the most suitable metal, and a square piece a little larger than required should be cut off, annealed, and cleaned, as before, and the design transferred and scratched in. Now mount the metal, trace the circles and leaves around the rim, there being no need to trace the large circles, because as the hollow will be formed from the face, a traced line is quite unnecessary. When this stage is finished take the metal up, clean off the 


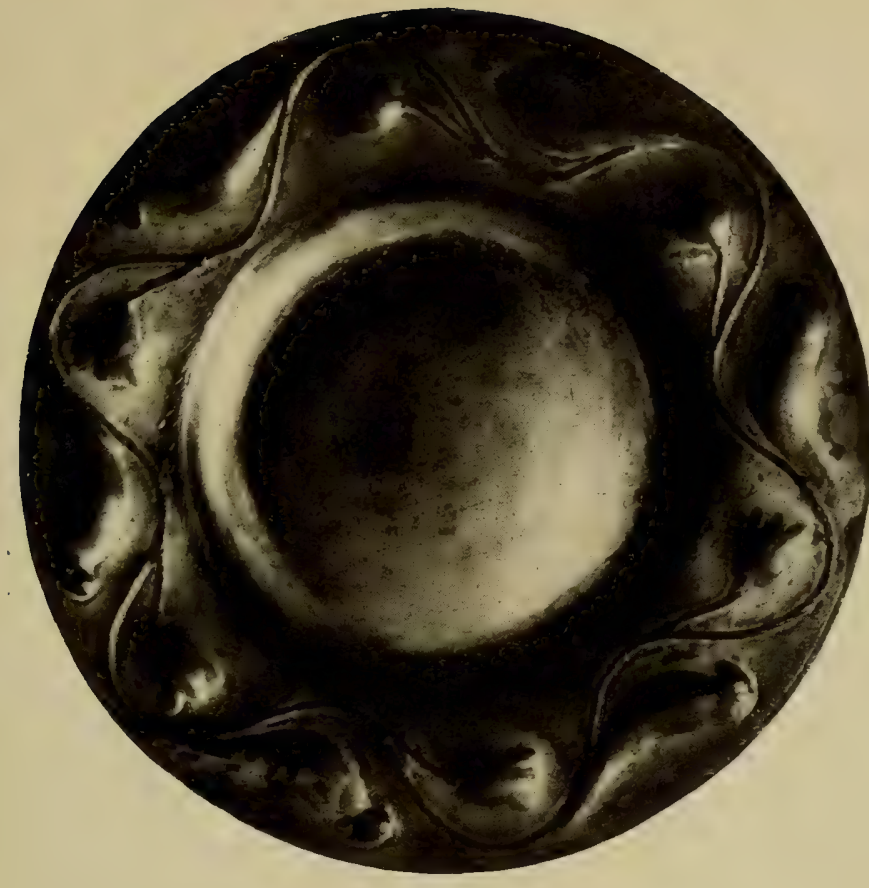

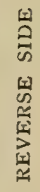

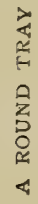

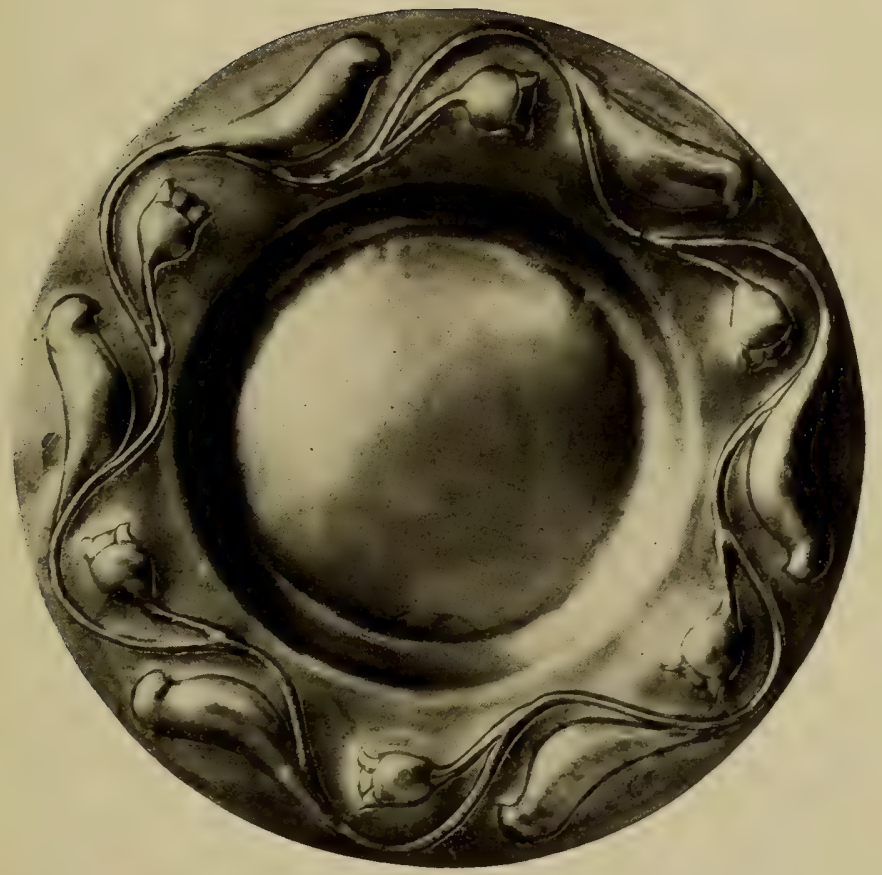

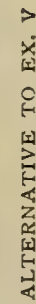





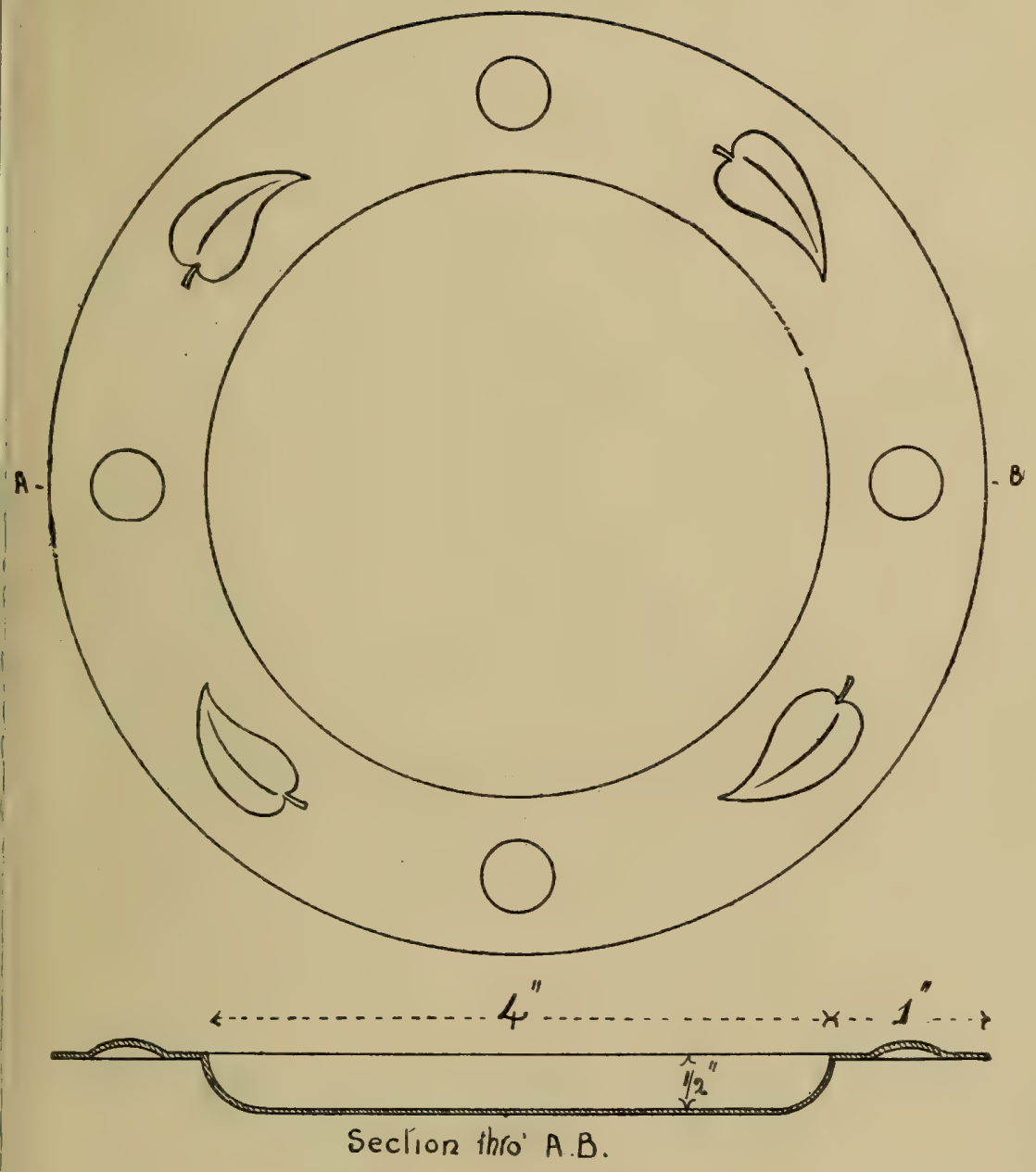

EXERCISE 5. A ROUND TRAY. 



\section{A ROUND TRAY}

pitch, and placing it on the sandbag, again work out, as fully explained in the last exercise. The depth is much greater in this case, and great care must be taken that the work is not done too quickly, or the result will be that the rim will be very much twisted and cockled. This will not, however, happen if the straightening out is done after every few blows. If the metal should prove hard and stubborn during the process of beating up with the mallet, anneal it again and repeat until it is quite soft. Metal becomes hard and brittle under repeated blows, and some pieces of work may require annealing several times.

When a satisfactory hollow has been wrought, fill it in with pitch as in the previous exercise and mount it face downwards on the block, and start working while it is yet warm, but not for some little time after mounting, just long enough for the pitch to set. Take a suitable round brass raiser and 
give a few light blows in each round. Do not attempt to reach the required depth at once, work a little at each in turn. The leaves will be a little more difficult. A fairly thin oval tool should be used on each side of the central mark, and with a small steel raiser these hollows should be brought to a clean edge. It is difficult to state exactly which tool is best for this work, but if a selection of the most useful is carefully made, it may be taken that the one which will do the work is the right one, so a little experimenting is desirable.

The worker must avoid a roughness of work at this stage, for slovenly raising only makes more work in the finishing stages, and if these rounds and leaves are worked smoothly from the back, they will require very little further finishing from the front.

The next step will be to finish the surface of the rim, and after taking the metal off, cleaning and remounting face upwards, a 
tracer should be run carefully round the base of each piece of raising, to bring it to shape and give the form sharpness (Fig. 30). Then take preferably a three-point punch and work the ground carefully. The hollow

\section{FIG. 30. PLAIN "BOSS."}

may be punched with a large round, or if the mallet work is well done and there are no marks in it, a plain surface will have just as nice an appearance. This will complete the model with the exception of trimming, cleaning, and lacquering. 


\section{EXERCISE VI}

\section{A MATCHBOX HOLDER}

THIs is an attractive model, and its utility, together with the introduction of a simple floral design, are important means of centring every attention.

Drawing. The freehand work in this drawing will prove a little difficult to those unaccustomed to that style of drawing, but as the original design is only given as an idea, any similar rendering of a suitable flower or piece of foliage will have the same effect. When one side is drawn, a tracing of it should be very carefully made, reversed, and redrawn on the other side of the centre line. It will be found that the blacklead has left an impression behind, which should then be pencilled over. 


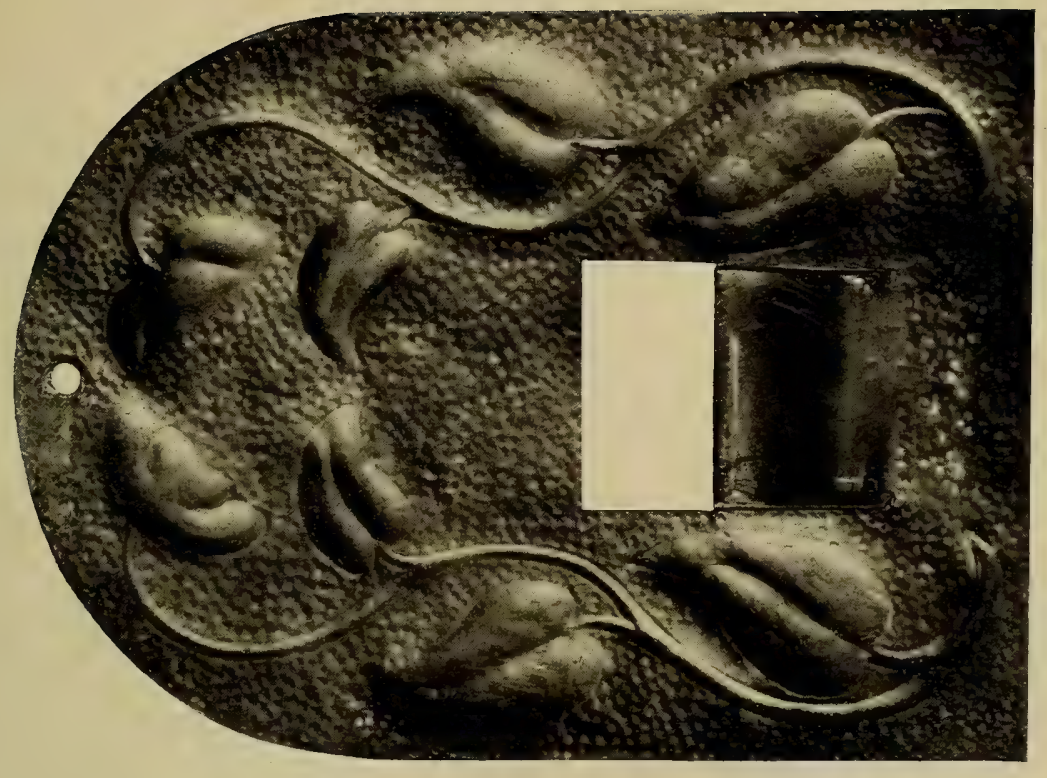

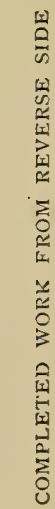

5
$\dot{x}$

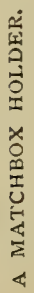

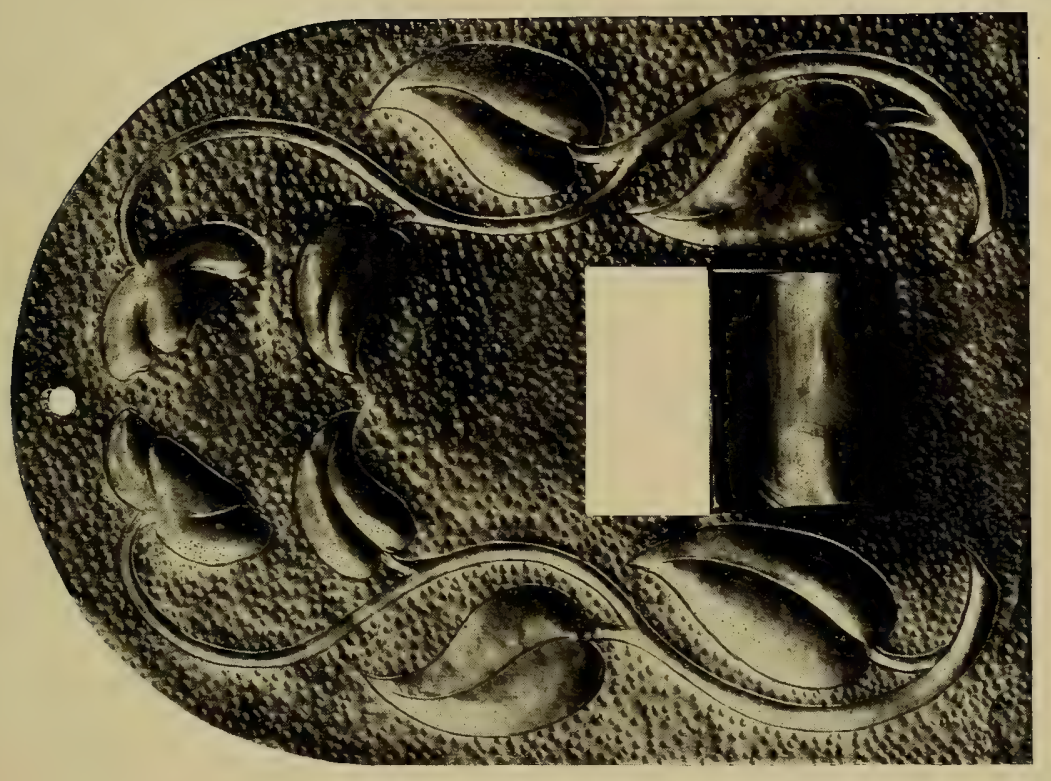

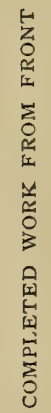





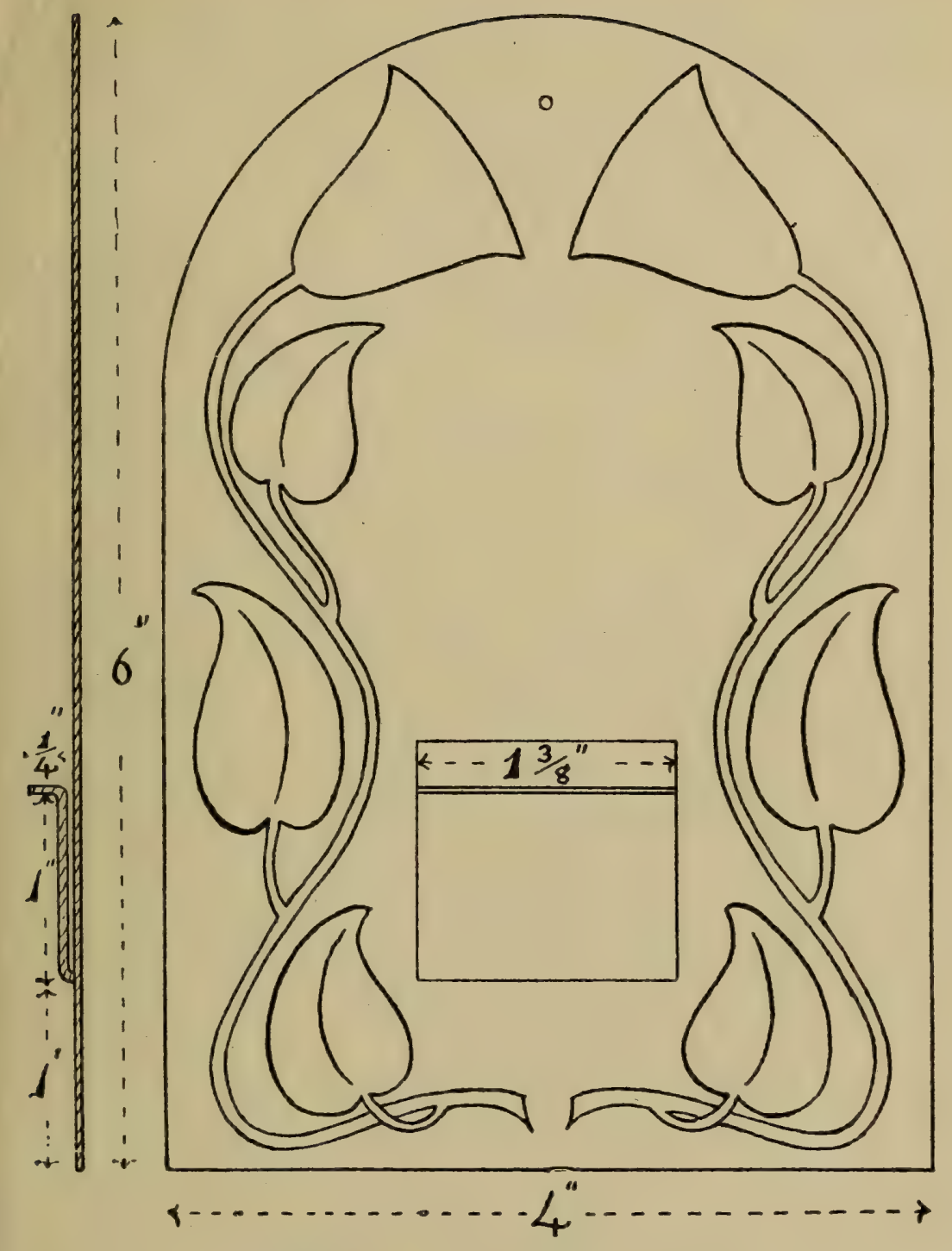

EXERCISE 6. A MATCHBOX HOLDER. 

Metalwork. This model looks well made in brass, so cut out a suitable piece, anneal and clean it, and trace on the design. Mount it on the block and trace the lines, owing to the small curves, the greatest care must be taken to avoid losing the line, and so spoiling the shape of the design. When this stage is completed, take the metal off, clean the pitch off, and placing it on the sandbag, slightly raise, with the small end of mallet, the flower and leaves, this is to avoid unnecessary work on the pitch. Now mount with face downwards and gradually work out shape of flower, making the top square and gradually tapering off to edges; the finished flower should show at the top a sharp edge which should be slightly undercut, but this will be explained fully when finishing. The leaves and stalk should be gradually worked in, taking care, particularly in the latter case, to avoid straining the metal too much, for if the tool work is done 
too quickly the metal may break, and so ruin its appearance. Over half a dozen different "raisers" will be required, but the worker should, as far as possible, confine his attention to a few rather than many. When the required depth is reached, the metal should be taken off the pitch, cleaned and replaced face upwards, and the finishing process begun. Many workers prefer a tooled effect on similar designs to this, but nothing looks nicer than the plain surface. The stalks, however, might be improved by a few parallel marks being tooled along them by means of a small, flat, raising tool. The most difficult part of the work will be experienced in truing up the shape and "undercutting" the top of flower. The latter work consists of rendering a sharpness to the edges; to give this finish to them, a flat tool must be used on the ground, slowly work from the edge by gentle hammering, and continue this until a flat ground is gained. 
In sharpening up and correcting the various shapes, it is necessary to use a tracer (Fig. 3I). When the design sufficiently stands out, and any irregularity on the surface has been taken out, the grounding, by means of a medium round, should be done. A saw or chisel may be used to cut through

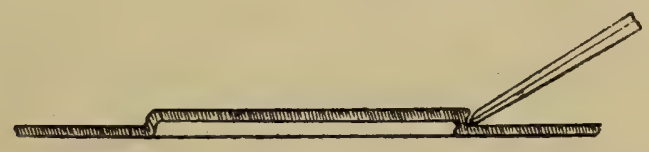

FIG. 3I. UNDERCUT "BOSS."

the lines, forming the clip of the matches, but this should be left until all trimming and polishing up is finished, it being much easier to polish the flat surface than leave it until after the clip is made. This latter operation is not difficult. When the metal is cut through, the edge should be filed and the top bent over with pincers and a slight spring given to it, to keep the matchbox quite firm. 


\section{EXERCISE VII}

\section{A FINGER PLA'TE}

THE increased difficulty of this exercise lies in the raising, which has to be done both with mallet and raising tools. It gives a good insight into the properties of the metal and its fibrous nature in resisting fracture.

Drawing. The front elevation and section will be sufficient to give a general idea of the shape, the actual form being mainly a matter of taste.

Metalwork. A piece of copper will be required somewhat larger than the given dimensions, and after well annealing, it should be cleaned with emery cloth and oil on both sides. The drawing should now be transferred to the best side of the metal by means of tracing and carbon 60 


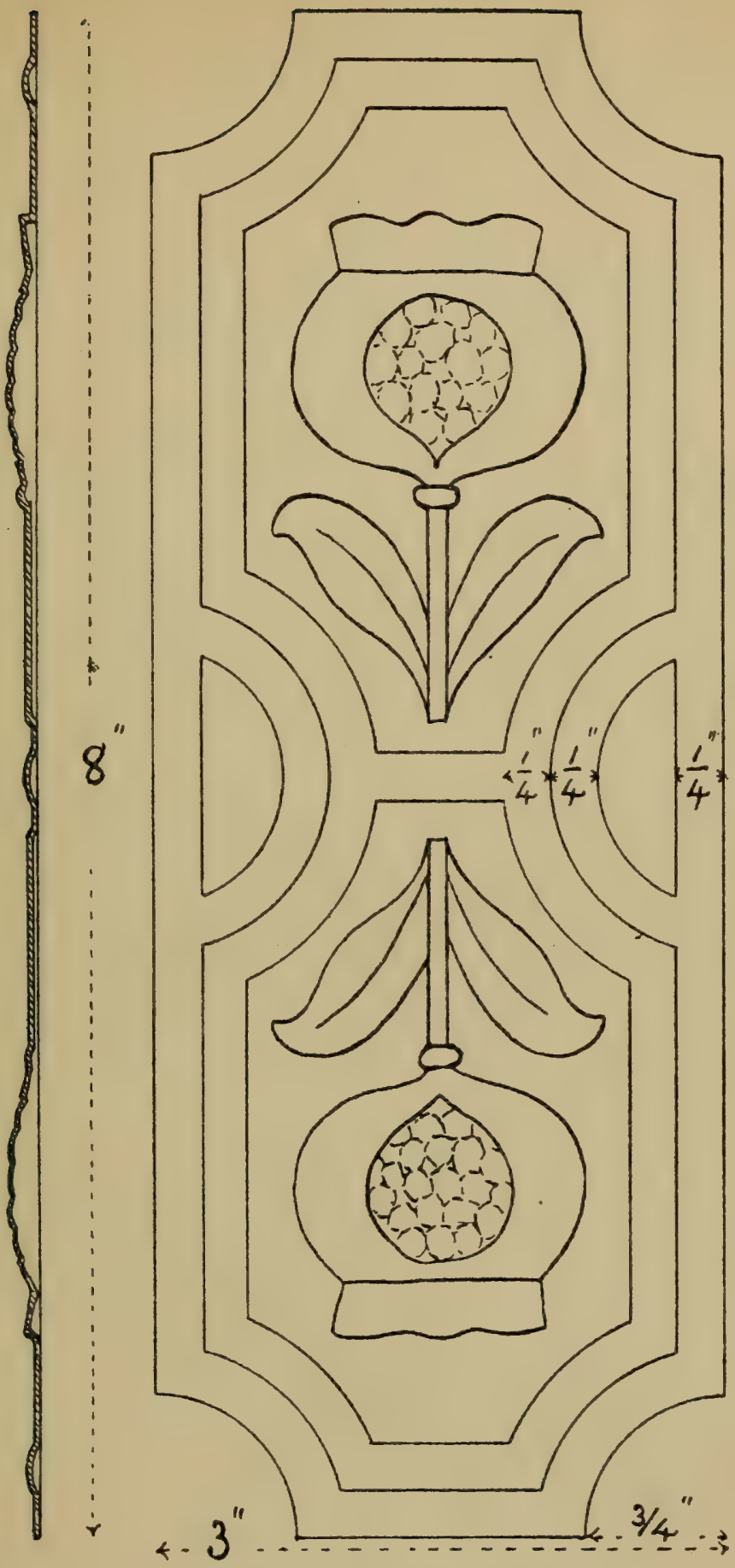

EXERCISE 7. A FINGER PLATE. 

papers, and then carefully scratched in with the scribing point.

The next step, that of mounting on the pitch block and tracing in the lines, will probably be very quickly done. Then after the metal is taken off, warmed, and cleaned up, it should be placed face downwards on the sandbag, and the raised portions carefully worked with the small end of mallet, paying great attention to the lines and avoiding any divergence from them.

When sufficiently raised, fill up with small pieces of pitch and place metal face upwards on the pitch, and with a large brass flat go round the shapes and bring the ground quite level. Now take metal off again, warm and clean up and replace face downwards, using now the necessary raising tools and working to proper shape. A pearl should be used to form the high relief of the seeds which are exposed by the split pod. A considerable amount of thought and artistic feeling 


\section{REPOUSSÉ METALWORK}

can be brought to bear in the several stages of the above raising, for the finished article should bear a resemblance, as far as can be shown in metal, to a seed-pod about to shed its contents.

When the raising has reached a satisfactory finish it should be taken from the block, warmed and cleaned, then the hollows filled up with pitch and replaced face upwards to finish. It may be necessary to repeat the last stages, but if the work has been thoughtfully done there should be no. need to take it off until quite finished.

There will be a considerable amount of work on the surface of leaves and pods to model them to an even form, but with the stock of tools provided and some patience a good finish should result.

A plain grounding with a rough matt will look best, special attention being directed to the raised parts, for the ground should occupy a secondary position. 


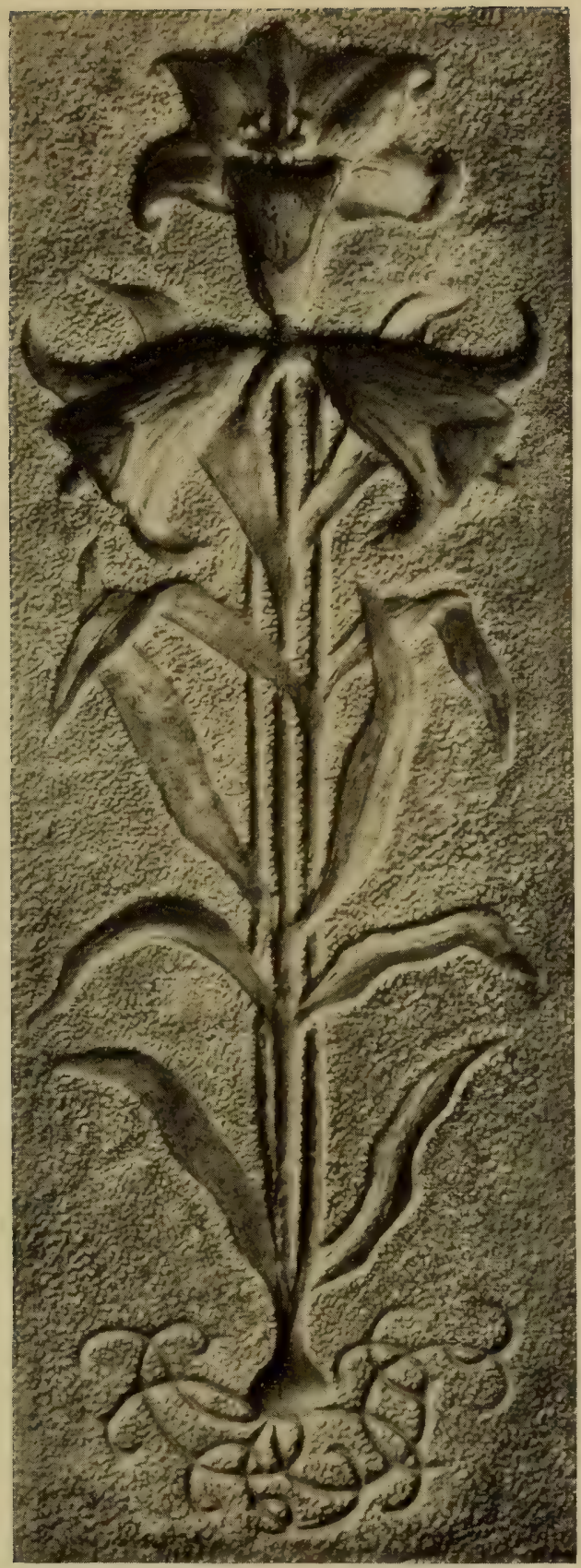

REPOUSSÉ l'ANEL IN HIGH RELIEF

(REVERSE SIDE) 



$$
\text { , }
$$




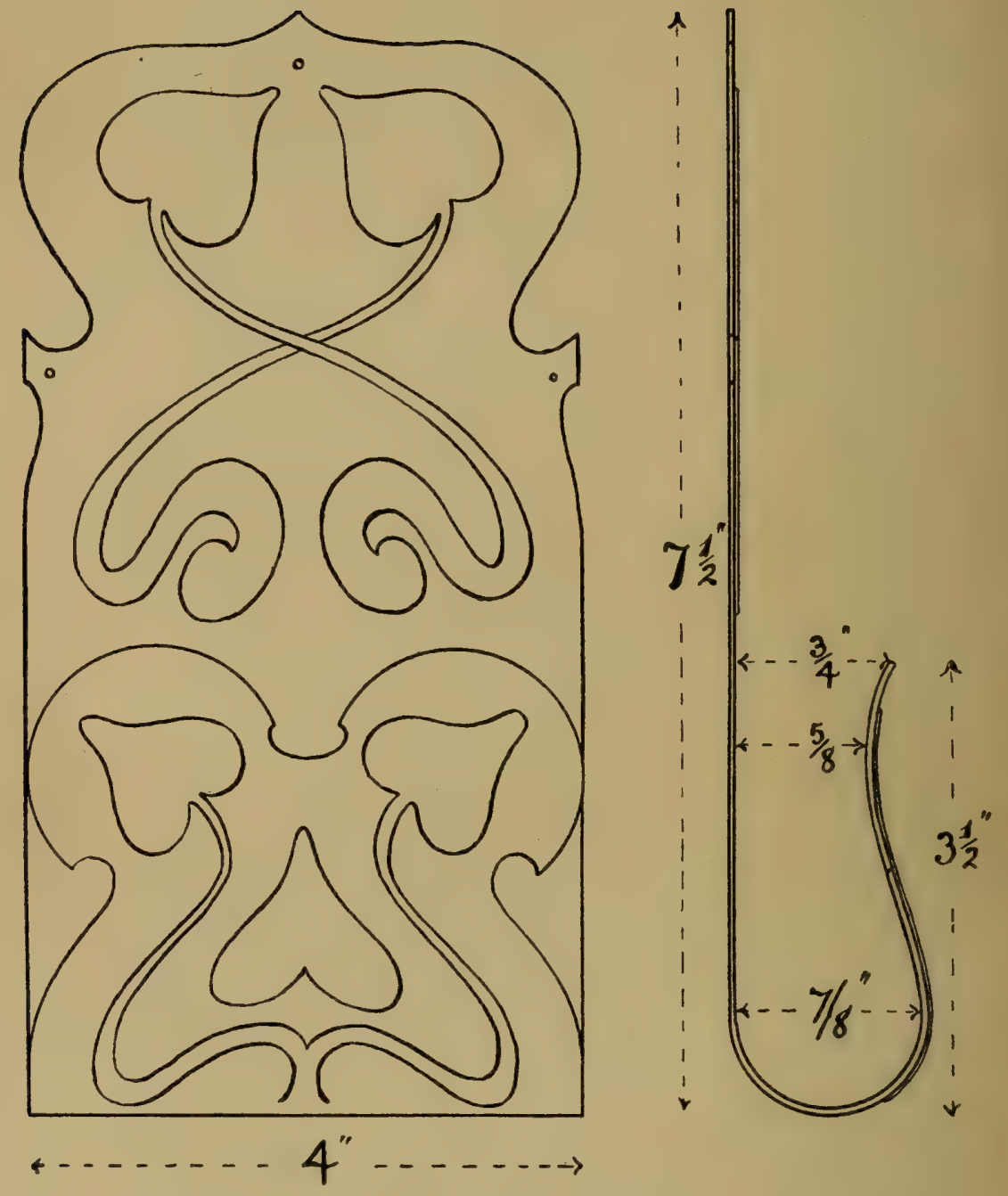

EXERCISE 8. A LETTER RACK. 


\section{EXERCISE VIII}

\section{A LETTER RACK}

Wiтh the exception of the bend, no new operation is introduced in this exercise. It forms good practice in raising.

Drawing. The views shown should be sketched, but as a working drawing the whole length, about I I in., should be drawn out, with design top and bottom.

Metalwork. Cut out the metal, allowing $I$ in. in length and $\frac{1}{2}$ in. in width extra, and after cleaning up transfer the top design and scratch it in ; next draw the lower design in on the other side, so that it may come to the front when the metal is bent up. The tracing should be done next, first at one end, and then metal reversed and the tracing finished on the other. Now model up the 
68

\section{REPOUSSÉ METALWORK}

design very slightly; the amount of relief should not exceed the thickness of the metal. When this part of the work is completed the ground should be punched if necessary; a careful worker would, however, have no need to cover the ground, for there should not be any marks if the raising has been well done. Next cut to shape and file up smooth, polish, and then bend to shape on the stake. This may easily be done by hand, with the least touching up with mallet afterwards. A hole should be bored at the top to enable it to be fastened up. 


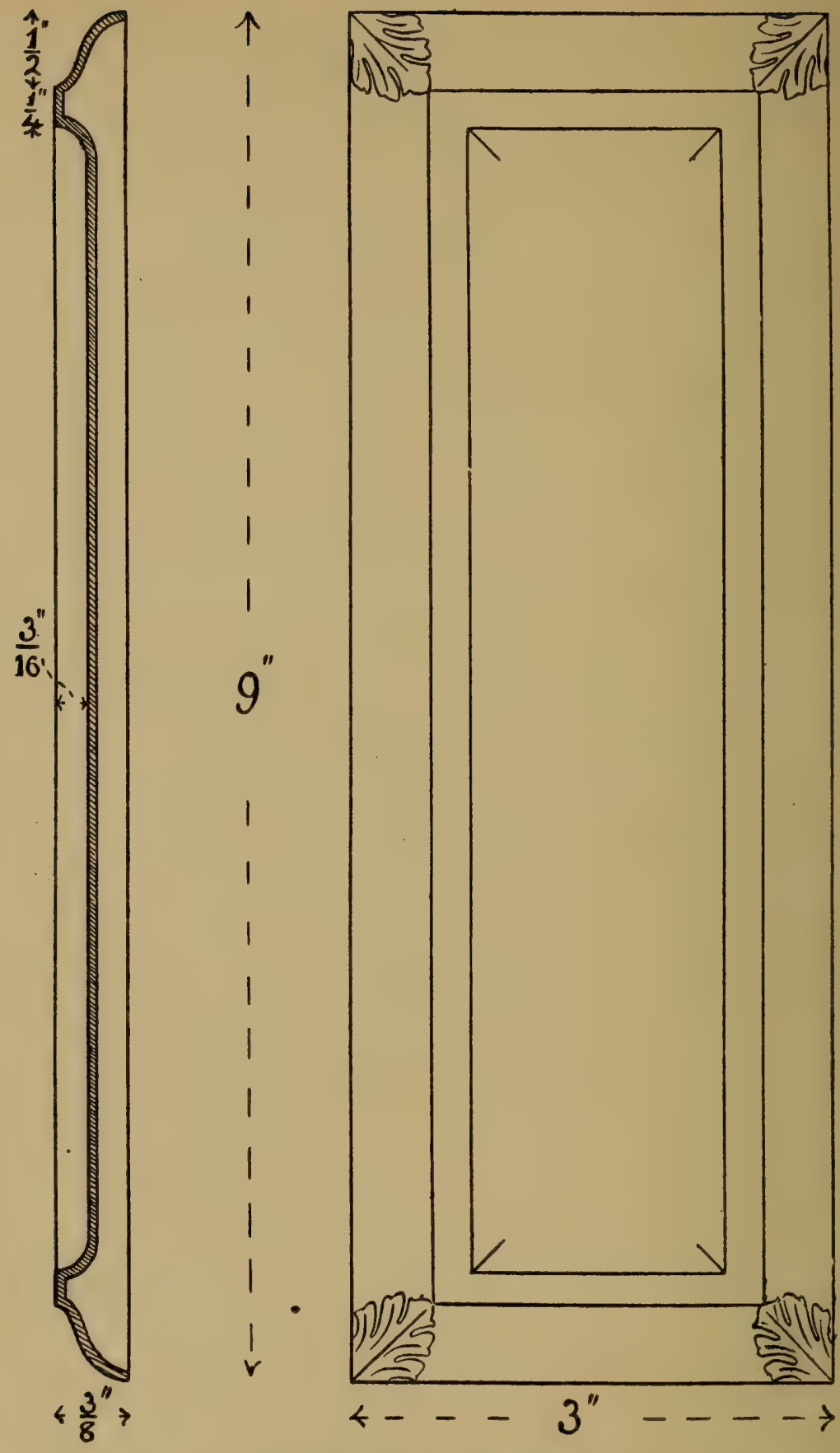

EXERCISE 9. A PEN REST. 


\section{EXERCISE IX}

\section{A PEN REST}

THIS is a distinct advance in raising, much of it being done both on the sandbag and on the pitch.

Drawing. The views shown, drawn to full scale, are all that is necessary.

Metalwork. First cut out a piece of copper about an inch larger each way, and draw on both sides the design. Next consider it without the hollow for pens, and raise the outside curve as near as possible on the sandbag; finish this on the pitch, taking it off and reversing several times until the correct shape is gained. Large brass raising tools will be best for this work. The depression in the middle should be done next, working the sand into 
the space to form a good pad, and gradually work the hollow down. It will be necessary to anneal a good many times, as the raising progresses, to keep the metal in a soft state. When ready for final finishing the leaves at each corner should be sketched in and traced, and then carefully tooled with a fine raiser. A medium pearl should be used to cover the groundwork and hollow, leaving the band on top quite smooth. Further ornamentation might easily be introduced to embellish the moulding. 


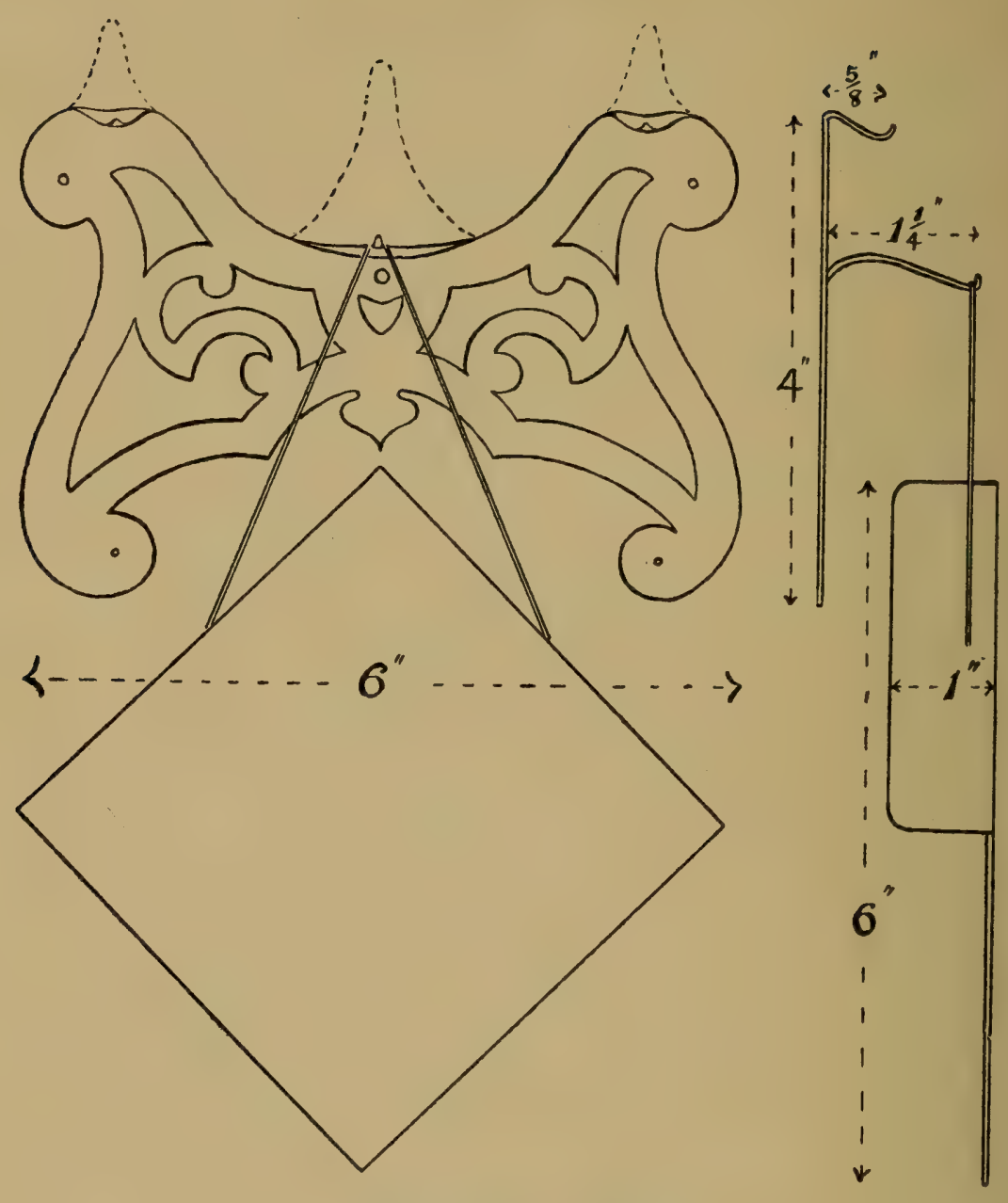

EXERCISE IO. A GONG. 


\section{EXERCISE $\mathrm{X}$}

\section{A GONG}

THIS exercise introduces pierced work.

Drawing. The two views will be sufficient to show the completed work.

Metalwork. Cut out a piece of metal, clean it up to a high polish, and transfer the design. Scratch in the lines very carefully, and then bore a small hole in each space to take the saw-blade. The fret-sawing is very similar to working on wood, but should be most cautiously done, allowing the saw to run freely without any attempt to force it. The outside shape should first be cut out, and then the inner spaces. When completed, finish with a small file or two to clean up all corners and true up shape.

Next polish up, and, if desired, burnish it; 
then bend over the projections into position, using the round-nose pliers to do this.

The gong will be found very simple. Cut out a larger piece of metal than is required for the finished article and mark it out, afterward mounting it on the pitch and punching it over with a large round. Some workers may prefer to work a pattern on the front of gong, and if so, proceed as for a flat tray. Cut out to shape and file quite smooth and true, then bend the two sides. Gauge the position of the holes and bore them, and hang up with a cord. The stick is easily made by binding a ball of cotton wool on one end of a round piece of wood and covering it with wash-leather. 



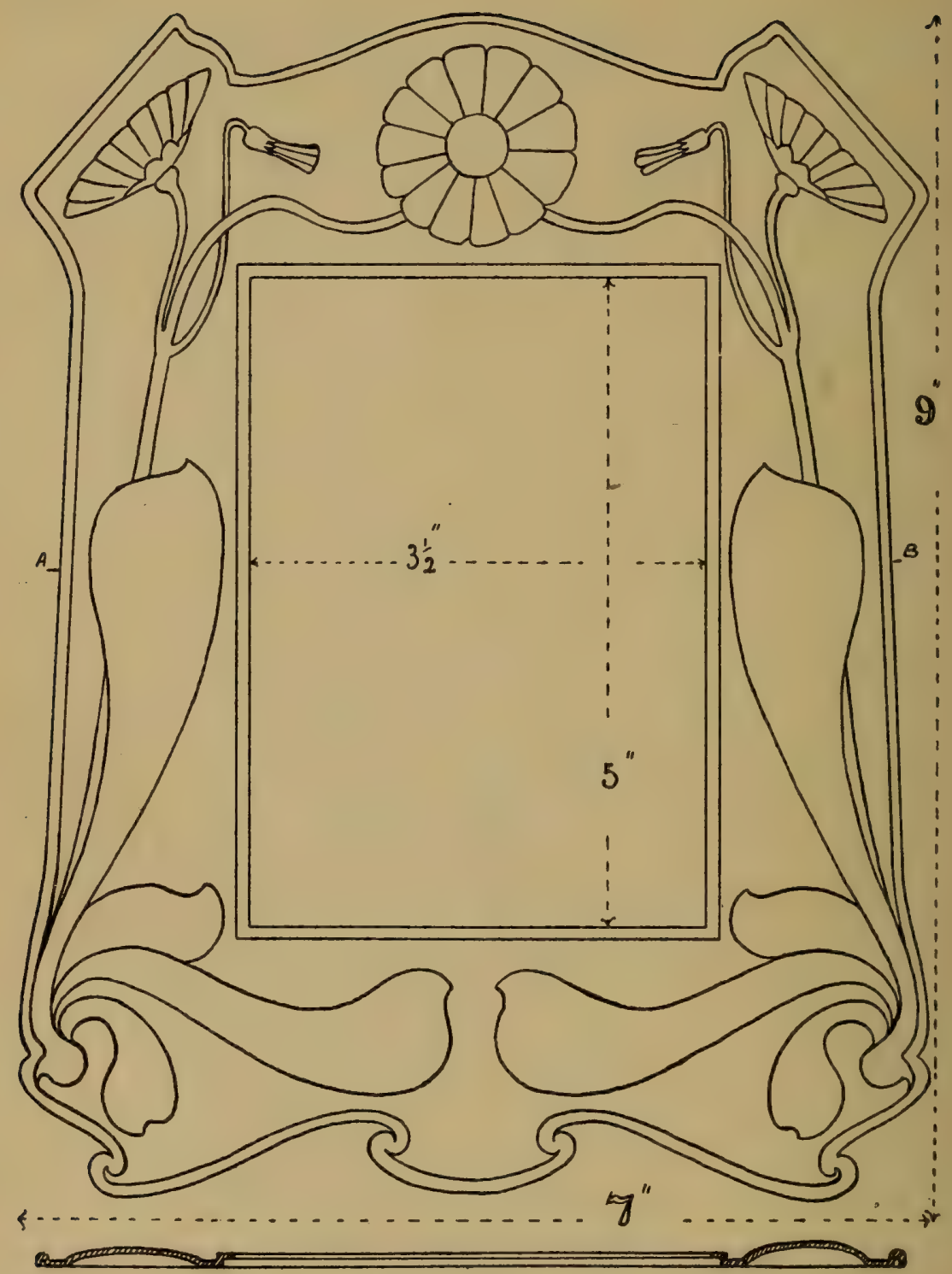

EXERCISE II. A PHOTO FRAME. 


\section{EXERCISE XI}

\section{A PHOTO FRAME}

Surface modelling is the principal feature of this exercise, which forms one of the most attractive in the course.

Drawing. The elevation and a section are given, but they are not sufficient to show exactly how each part should be treated; much will have to be left to the good taste of the worker.

Metalwork. The piece of metal to be used for this exercise will require much annealing, on account of the sharp edges of many parts of the design. After cleaning and scratching in the design, mount it and carefully trace the lines. When this is done, remove it from the block, clean it, and place it on sandbag. The most prominent parts 
should be raised with the mallet, also the centre space for the photo; this should be raised up about a quarter of an inch evenly. Now it should be mounted, and the whole of the design raised, with the central part brought out square and flat, as well as the outside rim. When finished, take it off the pitch, clean up, fill in the hollows, and replace face upwards. The next step should be to model the flowers and leaves, and then true up the edges of the rims. If the working has been carefully done the rims may be left plain, but some grounding, preferably a mat, should be worked around the design.

Take the metal off the pitch, and when cleaned up and partly polished cut out the centre, carefully filing up the edges, and then finally polish.

The frame may either be mounted on a piece of wood, or a stay soldered at the back to enable it to stand on a table. 


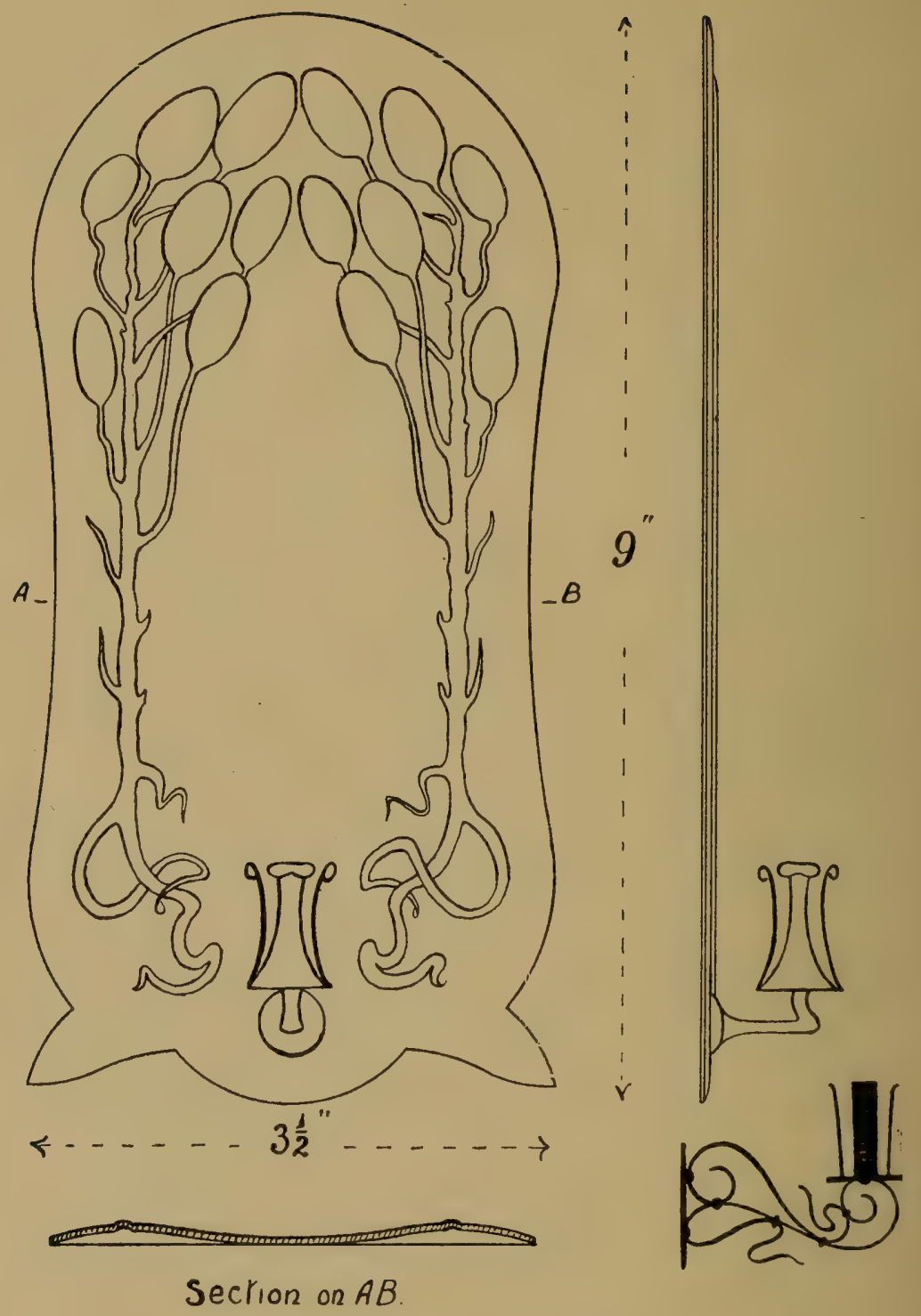

EXERCISE I2, A SCONCE. 


\section{EXERCISE XII}

\section{A SCONCE}

THis exercise gives good practice in modelling on the face or front of work.

Drawing. Some careful freehand will be needed here to get a good design, one side being transferred from the other, to get symmetry.

Metalwork. First prepare a piece of metal, clean up and transfer the design, mount it and trace the lines in. Now remove the metal and slightly raise from the outside all round, as shown in section, the centre being slightly hollowed will serve as a reflector. Next place the metal on pitch face downwards, and slightly raise the design, the stalk most of all, but that only slightly; then reverse the work and model the design 
into shape, and grounding with a round or matt just the raised or rounded portion all round, allowing the marks to gradually diminish as the central hollow is reached, which must be left quite plain. Cut to shape, file up, and give the whole surface a brilliant polish.

Next fix on the bracket; this may be made with a dresser-hook on which a piece of metal is soldered or brazed of the same shape as that shown in the drawing, and the screw end filed off and brazed on to the back. A screwed holder could be purchased and secured by a small bolt at the back, or those workers who are proficient in bent iron could easily form a bent-iron holder as suggested in the sketch. 


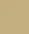



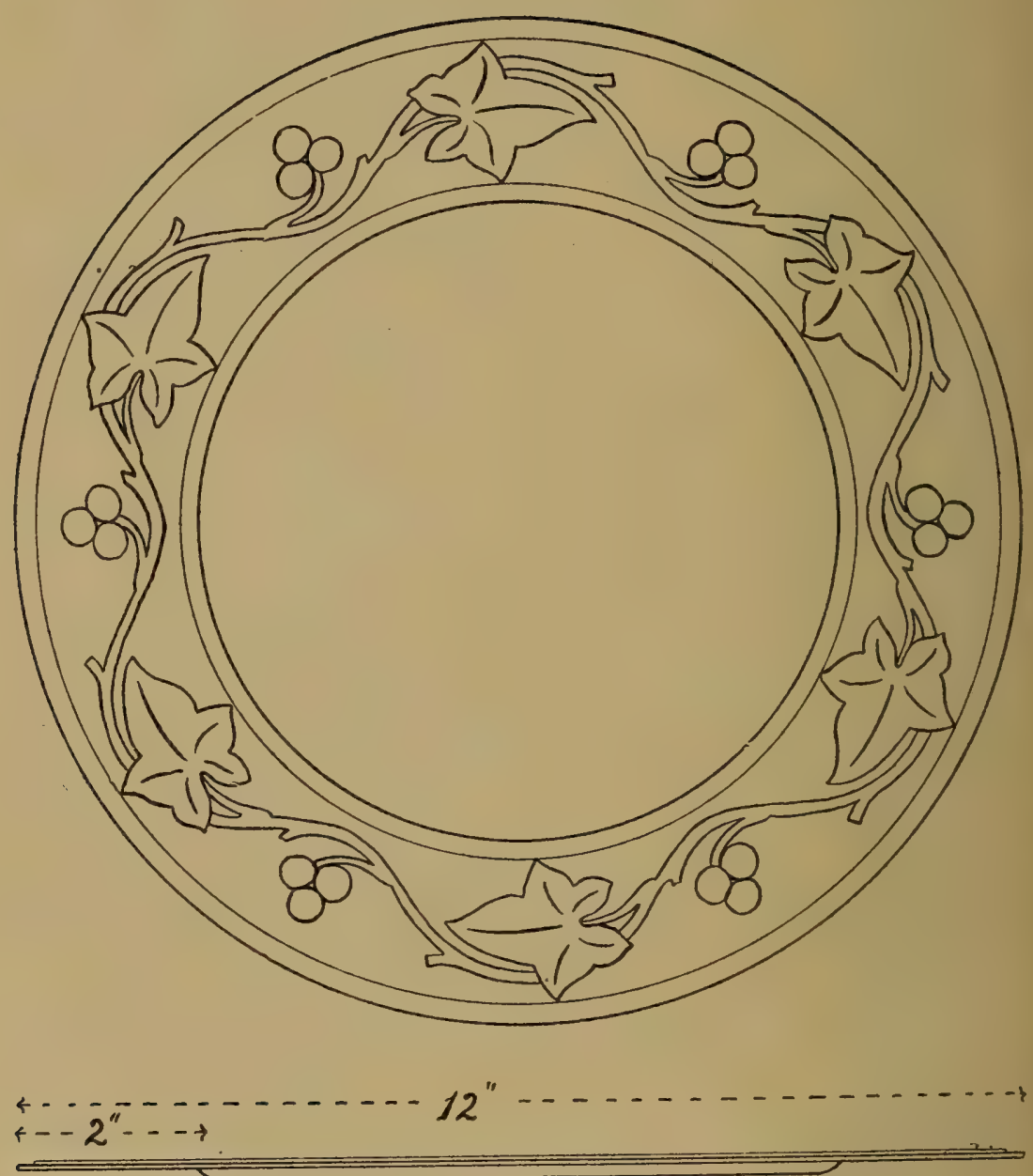

EXERCISE I3. A SALVER. 


\section{EXERCISE XIII}

\section{A SALVER}

THIs is a much larger piece of work, but as it contains no new operation, there should be little difficulty experienced in making it.

Drawing. The circles representing the tray should first be drawn, and the design in one segment of it drawn. As this is repeated six times by means of tracing paper, there is no need to draw the whole of it.

Metalwork. Choose a good piece of metal without the trace of a flaw, and after getting it straight, clean it thoroughly, giving the emery a circular motion starting from the centre, and working in concentric circles to the outside. Transfer the design and 
carefully scratch in the carbon lines. Now mount the metal and trace the design only, leaving the circular lines for the compasses. Next take off the work from the block, clean it and beat out the hollow centre on a sandbag: this being a very large hollow, the mallet work should be very carefully done. Starting from the centre, the mallet blows should work in concentric circles until the outside is reached, and after taking the twist out of the rim, the work should be continued until the required depth is reached. It should be remembered that this part is to be plain, so that no unsightly mark should on any account be left to mar the appearance of the finished article. To get a perfectly flat base, the block should be used to remove any dents that cannot be removed on the sandbag.

The next step will be to raise up the design of the ivy leaves, which only require very flat relief; but very careful work will be 


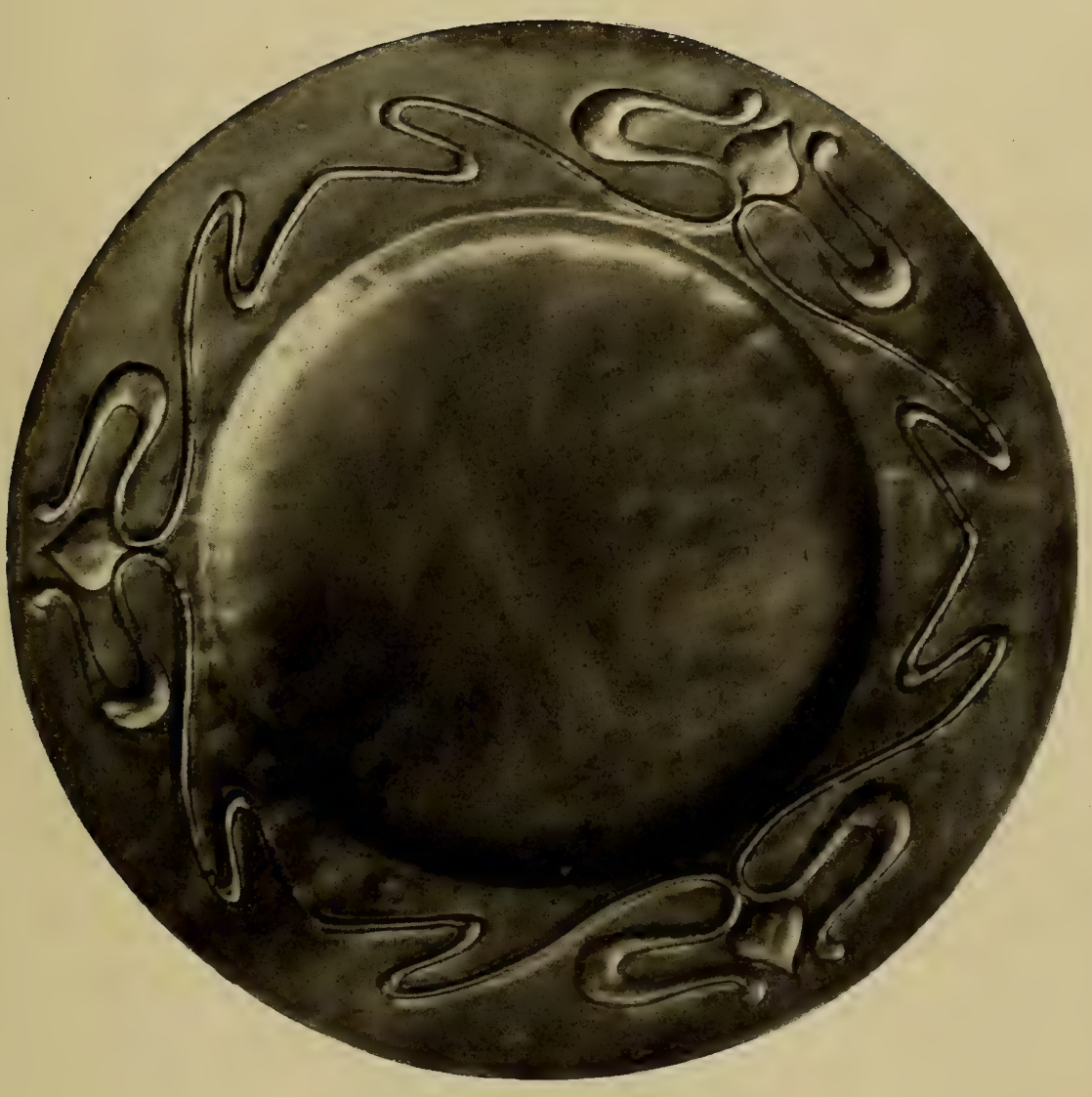

A CIRCUlar Pl.AQUe 

needed to give a naturalistic appearance to the leaves.

In the final surface modelling a very flat brass tool will come in very useful. Care should be taken that the edges of the leaves are slightly undercut to bring out the sharp corners and edges to a finish.

The final polishing should be most thoroughly done; in so large a piece of work the slightest blemish will readily be seen, it therefore calls for most careful work.

In lacquering it will be advisable to place the tray in an oven, and when hot enough the brush should follow the lines made by the emery cloth when first cleaned. 


\section{EXERCISE XIV}

\section{A DECORATIVE PANEL}

THIS exercise forms an example of very slight relief and some considerable surface work in the modelling of the leaves, stalk, etc., of the plant form. It contains excellent practice in tracing.

Drawing. The elevation will be enough, one side being drawn first, and transferred by means of tracing paper to the other side.

Metalwork. Carefully prepare the metal, taking out every mark, and giving it a good surface. Next trace on the design, scratch it in, and mount on the block.

The tracing will require great care, if the fine curves of the drawing are to be kept. When finished, the metal should be removed, and after cleaning up, placed on the sandbag 


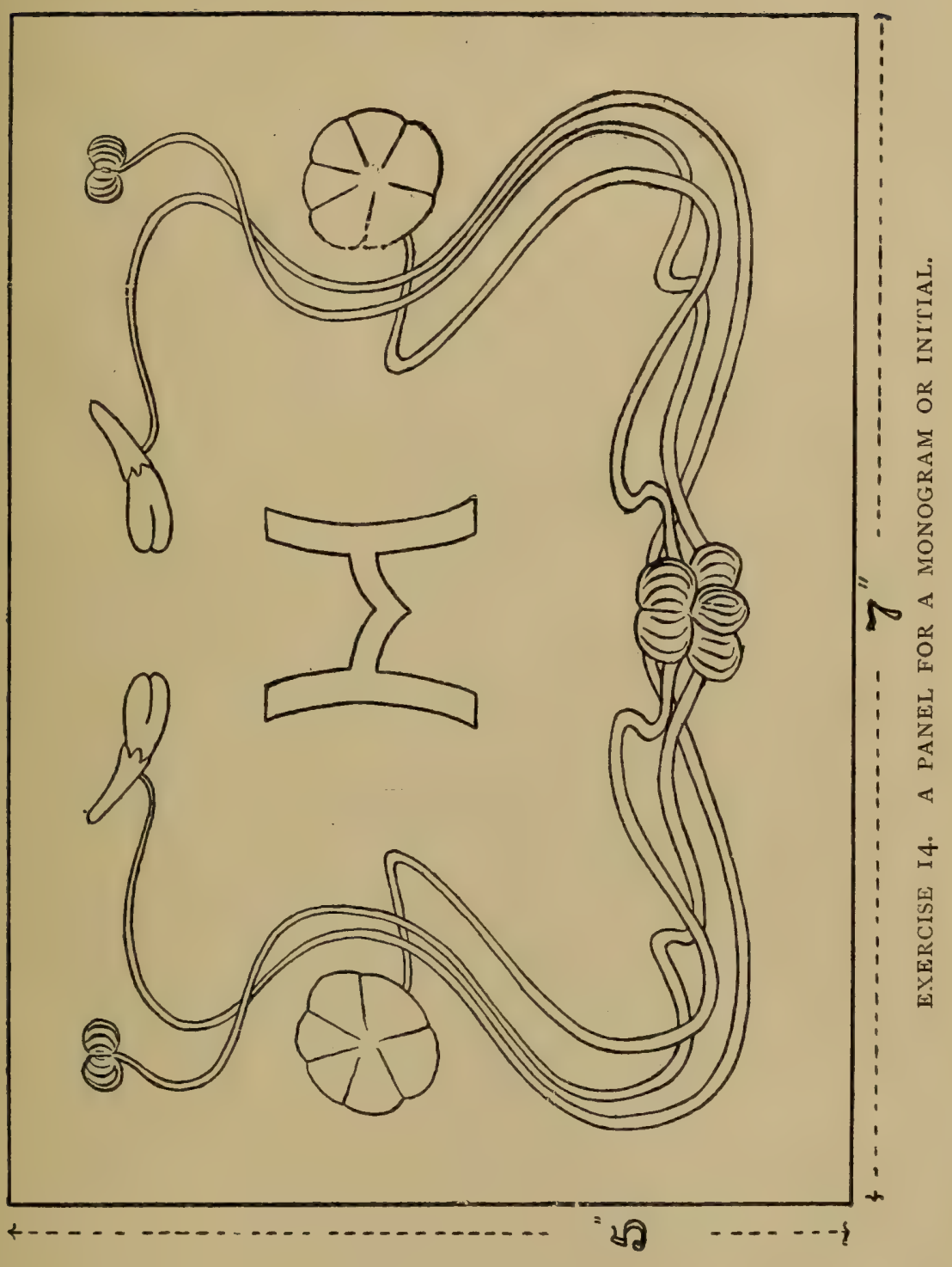



and carefully hollowed from the back. This operation requires great care, for the amount raised up is so slight and gradual, that the slightest mark made by a heavy blow of the mallet will show. Now it may be mounted face downwards, and the stalks, leaves, etc., slightly raised, the monogram being a little more prominent than the design. When this stage is completed, remove the metal, warm and clean up, and replace face upwards, and carefully work the leaves and stalks quite smooth; this will take time, for unless it is slowly done the surface will become lumpy. A slight undercut should be given with a tracer, carefully tooled around the lower edges of both stalks and leaves. The ground in this exercise may be left plain or punched with a plain round, and when finished, well polished up. 


\section{EXERCISE XV}

\section{A POSTCARD RACK}

THIS is an example of raised and pierced work, as well as bending.

Drawing. It will be advisable to make a plain working drawing without any attempt at suggesting the curvature of the front.

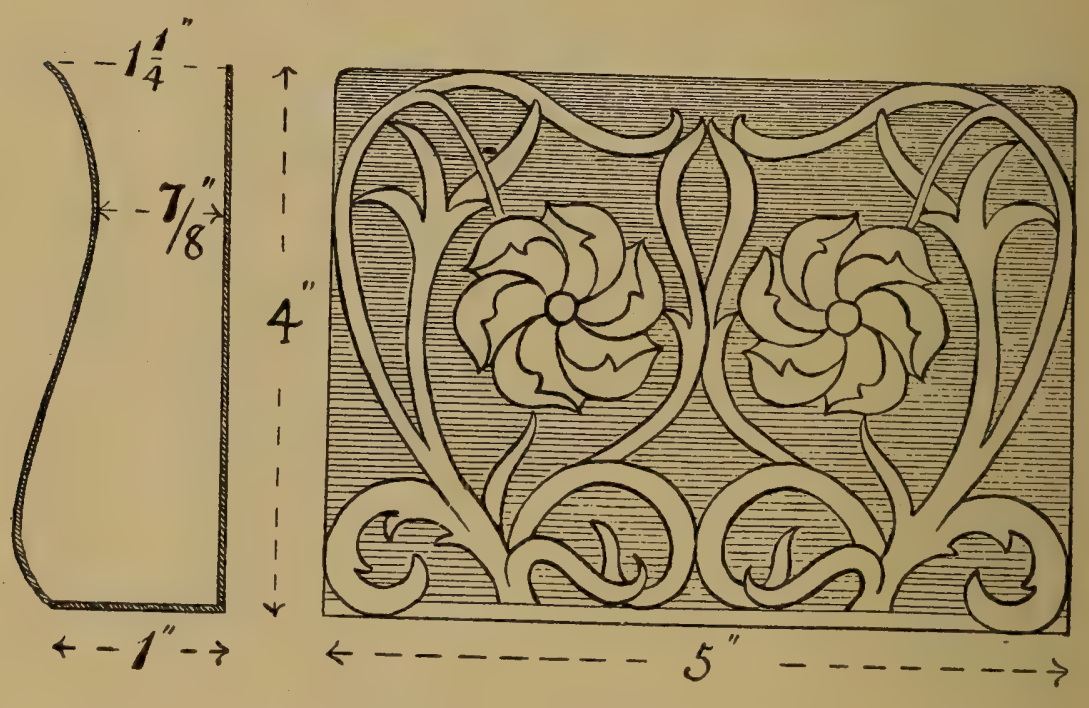

EXERCISE I5. A POSTCARD RACK. 
Metalwork. Proceed exactly as in the case of ordinary raising, but when the raising is finished, cut out the ground instead of punching it. This will be done exactly as in the pierced work of the gong holder, but of course being raised, the work will be more difficult. 


\section{EXERCISE XVI}

\section{AN ELLIPTICAL TRAY}

THE treatment of the edge is a new operation, but is not very difficult.
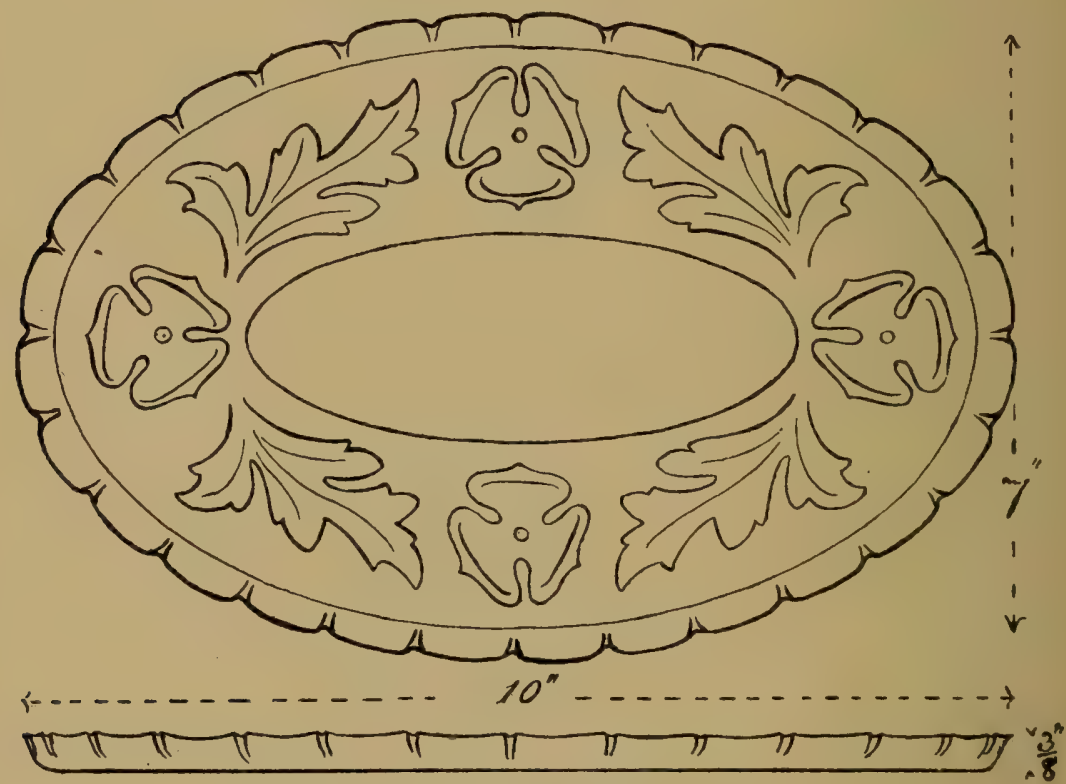

EXERCISE I6. AN ELLIPTICAL TRAY.

Drawing. A working drawing should be made, using either string or paper trammel. 
Metalwork. After tracing and working out the design, which may or may not be raised, according to taste, cut to exact shape and carefully file and smooth up the edge. Next step off with dividers the centres of

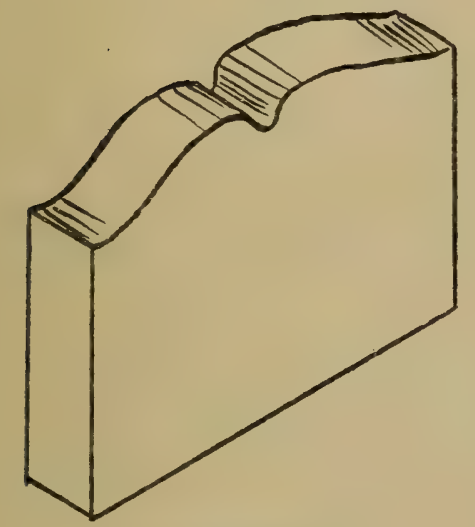

FIG. 32 .

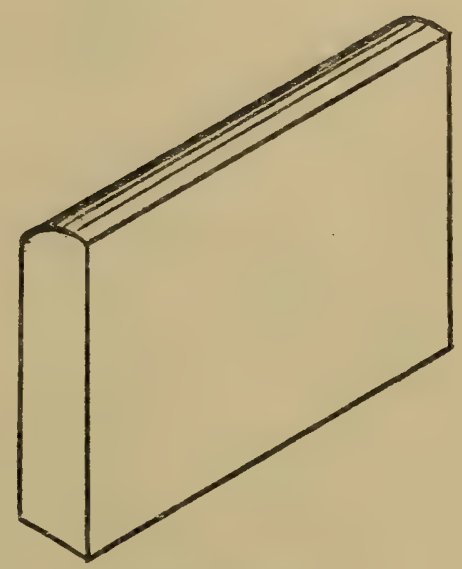

FIG. 33 .

BLOCKS FOR BENDING TRAY EDGE.

the small depressions, bend up the edge, and then using a block shown in Fig. 32, hit these in with a hammer, using the small end (Fig. 2), then bend over the metal between these ridges, with the small end of the mallet on another block, shaped as in Fig. 33. 


\section{EXERCISE XVII}

\section{A CLOCK CASE}

THIs forms a useful model, and may be adapted to any round clock.

Drawing. The views shown should be drawn.

Metalwork. Straightforward work will be needed in this exercise. The opening for the clock being made to exact measurement, and after being treated in the same way as if for a tray, the bottom should be cut out. Of course, the deeper the depression can be made, the more secure the clock will be held.

The top is worked out exactly in the same way as Exercise II., and fitted on afterwards. 

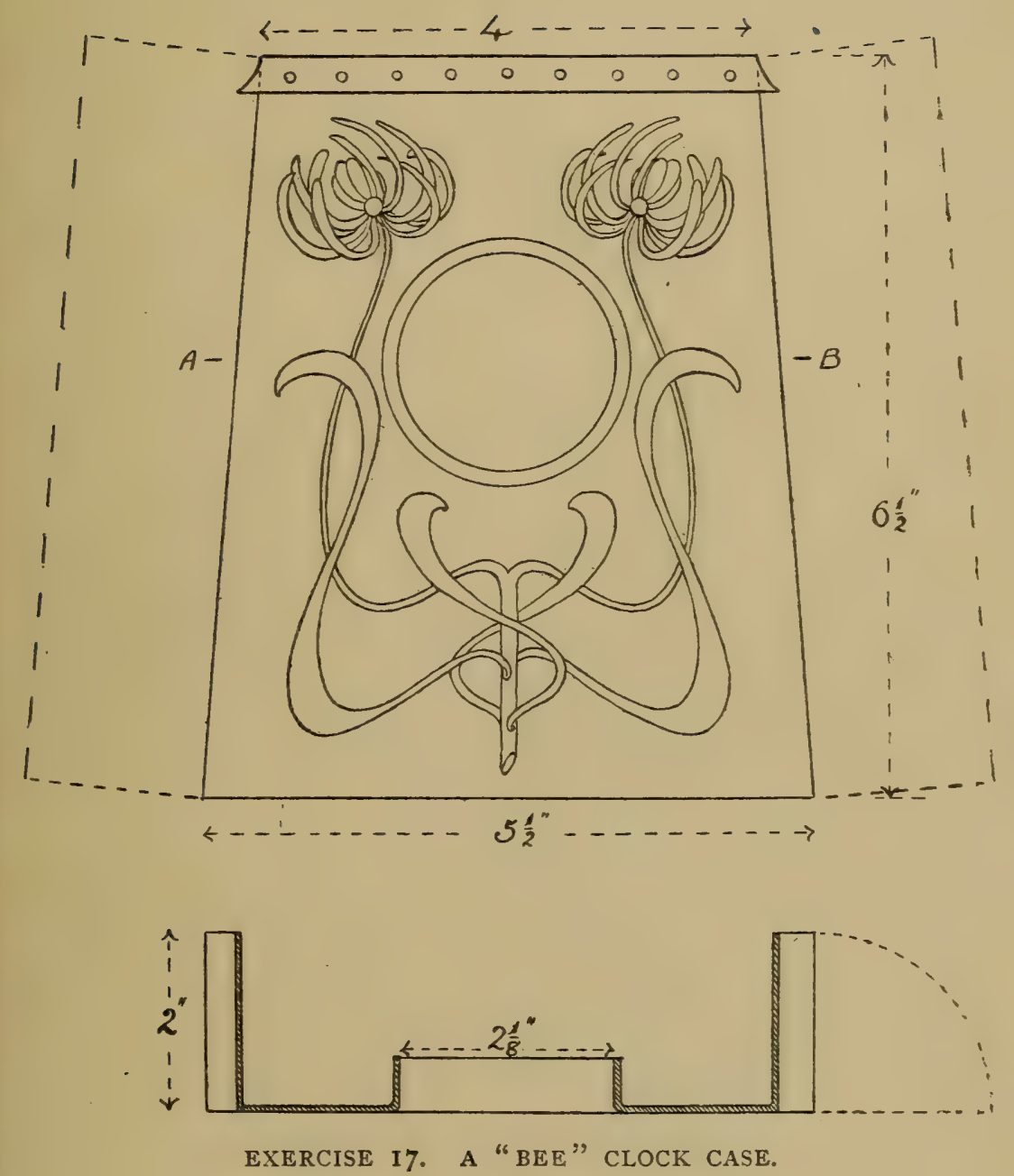



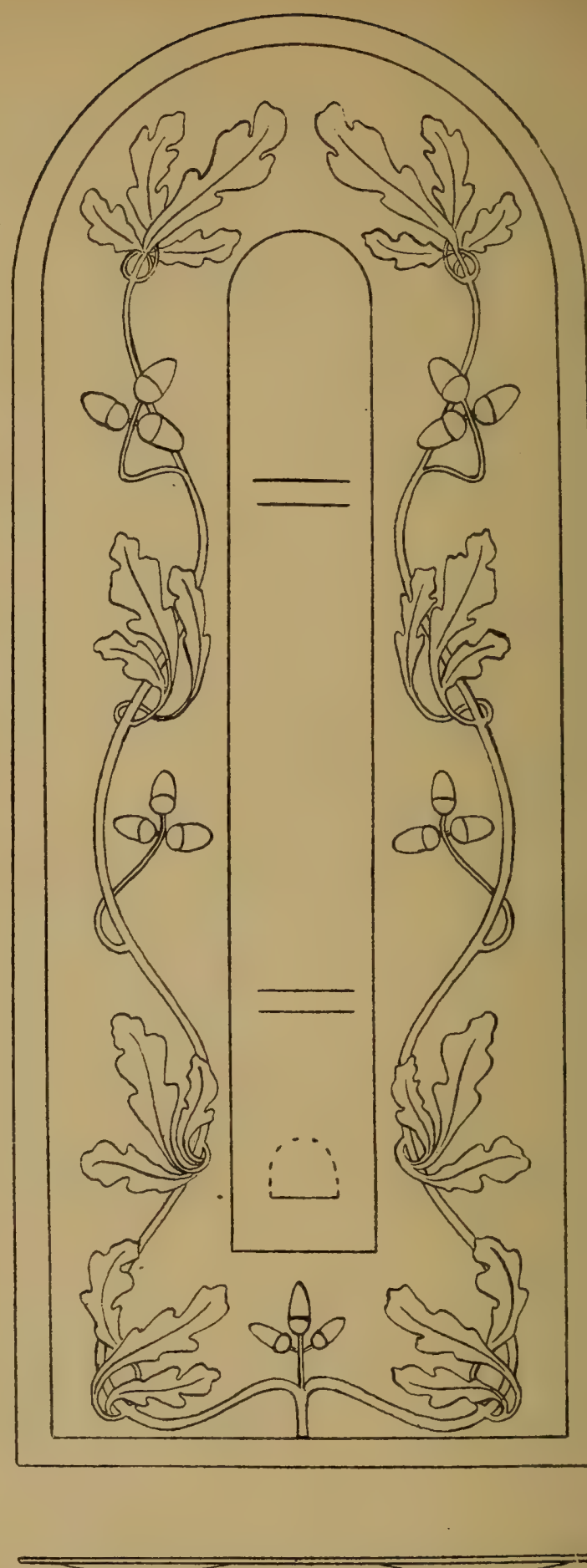

EXERCISE I8. A THERMOMETER STAND. 


\section{EXERCISE XVIII}

\section{A THERMOMETER STAND}

THE modelling in this exercise will take a lot of care if the rendering of the oak is to be at all naturalistic.

Drawing. The given design is only a suggestion, and another arrangement could easily be devised.

Metalwork. The only difficulty will be fitting in the thermometer, and to do this the spaces shown by the parallel lines should be well opened out, so that the tube may be easily inserted. The semicircular piece to hold the bulb should then be turned outwards, and finally the holding strips pushed in each side of the tube to keep it firm. 
PLYMOUTH

WILLIAM BRENDON AND SON, LTD.

PRINTERS 


\section{A LIST OF EDUCATIONAL WORKS PUBLISHED BY METHUEN AND COMPANY PUBLISHERS : LONDON 36 ESSEX STREET W.C.}

CONTENTS

\begin{tabular}{|c|c|c|c|c|c|c|c|}
\hline & & & & & & & PAGE \\
\hline COMMERCE & . & - & - & - & - & - & 3 \\
\hline DIVINITY & - & - & • & $\bullet$ & - & - & 3 \\
\hline DOMESTIC SCI & NCE & - & • & - & - & - & 4 \\
\hline ENGLISH & - & - & - & - & - & - & 4 \\
\hline FRENCH & - & - & - & . & - & - & 7 \\
\hline GENERAL & - & . & - & - & - & - & 7 \\
\hline GEOGRAPHY & - & - & - & - & - & . & 8 \\
\hline GERMAN & . & - & . & . & . & - & 8 \\
\hline GREEK - & - & - & - & - & - & - & 9 \\
\hline HISTORY & . & - & . & - & - & - & 10 \\
\hline LATIN • & - & - & - & - & - & - & II \\
\hline MATHEMATICS & - & - & . & - & - & - & $I_{3}$ \\
\hline SCIENCE & - & - & - & - & - & - & $I_{4}$ \\
\hline TECHNOLOGY & - & - & - & - & . & - & $x 6$ \\
\hline
\end{tabular}

Messrs. Methuen Will BE GLAd TO SEND THEiR Complete Catalogue or Prospectuses of aNy OF their SERIES TO ANY AddREsS, POST FreE, ON APPLICATION 


\section{NOTE}

MESSRS. METHUEN will be happy to receive applications for Specimen Copies of any of their School Books from boná-fide Teachers. Specimen Copies of many of their School Books are supplied gratis, but a charge must be made in all cases for books marked with a dagger $(\dagger)$ in this List. Specimen Copies of Keys are not given.

A copy of any book in this List can be seen at Messrs. Methuen's offices, 36 Essex Street, Strand, W.C., and most of them may be consulted at the Library of The Teachers' Guild, 74 Gower Street, W.C., and at the Library of the College of Preceptors, Bloomsbury Square, W.C. A copy of each of Messrs. Methuen's Educational Books is sent to the Education Department Libraries in the Colonies.

Books marked with an asterisk $\left(^{*}\right)$ are now in the press, and will be issued shortly. 


\section{MESSRS. METHUEN'S Educational List}

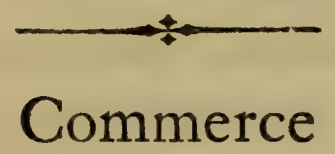

+ Commercial Education in Theory and Practice. By E.

E. Whitfield, M.A. Crown 8vo, 5 s.

Treats of the whole question of Commercial Education. Reliable information as to the work done by young clerks in modern business establishments is given, also hints as to the bearing of school work on such duties. A number of examination papers and lists of books are included.

t A Guide to Professions and Business. By Henry JONES. Crown 8vo, Is. 6d.

Précis Writing and Office Correspondence. By E. E. Whitfield, M.A.- Second Edition. Crown 8vo, 2s.

+ Commercial Examination Papers. By H. DE B. Gibins, Litt.D., Headmaster, King Charles I. School, Kidderminster. Papers on Commercial Geography and History, French and German Correspondence, Book-keeping, and Office Work. Crown 8vo, Is. 6d.

The Economics of Commerce. By H. DE B. Gibbins, Litt.D. Crown 8vo, Is, 6d.

A Primer of Business. By S. JAckson, M.A. Third Edition. Crown 8vo, Is. 6d.

Commercial Law. By W. Douglas Edwards, LL.B. Crown $8 \mathrm{vo}, 2 \mathrm{~s}$.

See also under "French," "German," "Geography," "History," "Mathematics."

\section{Divinity}

* The First Book of Kings. Edited by A. E. Rubie, D.D., Headmaster of Eltham College. Is. 6d.

The Gospel according to St. Matthew. Edited by E. Wilton South, M.A. With Three Maps. Crown 8vo, Is. 6d.

The Gospel according to St. Mark. Edited by A. E. RUBIE, D.D. With Three Maps. Crown 8vo, Is, 6d. 
* The Gospel according to St. Luke. Edited by WilliaM Williamson, B.A. With Three Maps. Crown 8vo, Is. 6d.

The Acts of the Apostles. Edited by A. E. RUBIE, D.D. With Three Maps. Crown 8vo, 2s.

The Students' Prayer Book. The Text of the Morning and Evening Prayer and Litany. With Notes by W. $\mathrm{H}$. Flecker, M.A., D.C.L., Headmaster of the Dean Close School, Cheltenham. Crown 8vo, 2s. 6d.

Old Testament History for use in Schools. By W. F. Burnside, M.A., Assistant Master in Cheltenham College. Crown 8 vo, 3s. 6d.

"The sense of proportion throughout is excellent, just what it should be in a school history. We may describe the attitude of the book as reverent, fearless, and honest. We hope the book will be widely used."-Guardian.

"We have no hesitation whatever in recommending this volume as the best of its kind now in use."-School World.

See also under "Greek."

\section{Domestic Science}

How to make a Dress. By J. A. E. Wood. Illustrated. Third Edition. Crown 8vo, Is. 6d.

"Though primarily intended for students, Miss Wood's dainty little manual may be consulted with advantage by any girls who want to make their own frocks. The directions are simple and clear, and the diagrams very helpful." - Literature.

Adopted by the London County Council Education Committee.

Millinery: Theoretical and Practical. By ClaRE HILL. With numerous Diagrams. Crown 8vo, 2s.

\section{English}

A Class Book of Easy Dictation and Spelling. By W. Williamson, B.A. Third Edition. Fcap. 8vo, Is.

A Class Book of Dictation Passages. By W. Williamson, B.A. Ninth Edition. Crown 8vo, Is. 6d.

In use at over three hundred Schools, including Bath College; Blackheath School; Bradfield College ; Fauconberge School, Beccles; Cheltenham College; High School, Dublin; Edinburgh Academy ; High School, Glasgow; Elizabeth College, Guernsey; Lancing College; Merchant Taylors' School ; Mill Hill School; Nottingham High School ; Owen's School, Islington; St. Olave's School, Southwark; St. Paul's School.

A Junior English Grammar. By W. Williamson, B.A. With numerous passages for Parsing and Analysis, and a Chapter on Essay-Writing. Second and Revised Edition. Crown 8vo, 240 pages, 2S.

+ Junior English Examination Papers. By W. WiLliamson, B.A. Fcap 8vo, Is. 
The Rose Reader. By Edward Rose. With numerous Illustrations, some of which are Coloured. Crown 8vo, 2s. 6d. And in Four Parts. Parts I. and II., 6d. each ; Part III., 8d. ; Part IV., Iod. Introduction for the Teacher separately, $6 \mathrm{~d}$.

A reader on a new and original plan. The distinctive feature of this book is the entire avoidance of irregularly-spelt words until the pupil has thoroughly mastered the principle of reading, and learned its enjoyment. The reading of connected sentences begins from the first page, before the entire alphabet is introduced.

† Tommy Smith's Animals. By Edmund Selous. With 8 Illustrations by G. W. ORD. Third Edition. Fcap 8vo, 2s. 6d.

A reading-book for kindergarten and junior school libraries.

Ballads of the Brave. Poems of Chivalry, Enterprise, Courage, and Constancy. Edited by F. LANGBRIDGE, M.A. Second Edition. Crown 8vo, 2s. $6 \mathrm{~d}$.

A Short Story of English Literature. By EmMA S. Mellows. Crown 8vo, 3s. $6 \mathrm{~d}$.

Finglish Poetry from Blake to Browning. By W. M. Dixon, M.A. Second Edition. Crown 8vo, 2s. 6d.

Suitable for University extension students and home reading circles.

Victorian Poets. By A. SHARP. Crown 8vo, 2s. 6d.

Suitable for University extension students and home reading circles.

A Primer of the Bible. By W. H. Bennett, M.A. Second Edition. Crown 8vo, 2s. 6d.

A Primer of Tennyson. By W. M. Dixon, M.A. Second Edition. Crown 8vo, 2s. $6 \mathrm{~d}$.

A Primer of Burns. By W. A. Craigie. Crown 8vo, 2s. 6 d.

A Primer of Wordsworth. By LaURie Magnus, M.A. Crown 8vo, 2s. 6d.

\section{THE LITTLE LIBRARY}

Pott 8vo. Each Volume, clotb, 1s. 6d. net.

Each, where it is necessary, contains an Introduction, which gives ( $x$ ) a short biography of the author; (2) a critical estimate of the book. Short notes are given at the foot of the pages.

+ A Little Book of English Prose. Edited by Mrs. P. A. BARNETT.

+ A Little Book of Finglish Lyrics.

+ A Little Book of Scottish Verse. Edited by T. F. HENDERSON.

+ The Farly Poems of Alfred, Lord Tennyson. Edited by J. Churton Collins, M.A.

+ The Princess, and other Poems. By AlFred, LORD TenNyson. Edited by Elizabeth Wordsworth.

+ Maud, and other Poems. By Alfred, Lord Tennyson. Edited by ELIZABETH WORDSWORTH.

+ In Memoriam. By AlFred, Lord Tennyson. Edited by H. C. Breching, 
+ Selections from Wordsworth. Edited by NowELL C. SMrTH.

+ Fothen. By A. W. KINGLAKe.

t Flia, and the Last Essays of Elia. By CHARLES LAMB. Edited by E. V. LuCAS.

tEsmond. By W. M. Thackeray. Edited by Stephen GWYNN.

A full list of this Series will be sent free on application.

† METHUEN'S UNIYERSAL LIBRARY

EdITED BX SIDNEY LEE. In Sixpenny Volumes.

Messrs. METHUEN are issuing a new series of reprints containing both books of classical repute which are accessible in various forms, and also some rarer books of which no satisfactory edition at a moderate price is in existence. It is their ambition to place the best books of all nations, and particularly of the Anglo-Saxon race, within the reach of every reader. All the great masters of Poetry, Drama, Fiction, History, Biography, and Philosophy will be represented. Mr. Sidney Lee will be the General Editor of the Library, and he will contribute a Note to each book.

The characteristics of MrThUEN's UNIVBRSAL LIBRARY are five :-

I. Soundness of TEXT. A pure and unabridged text is the primary object of the series, and the books will be carefully reprinted under the direction of competent scholars from the best editions.

2. Completeness. Where it seems advisable, the complete works of such masters as Milton, Bacon, Ben Jonson, and Sir Thomas Browne will be given. These will be issued in separate volumes, so that the reader who does not desire all the works of an author will have the opportunity of acquiring a single masterpiece.

3. ChEAPNESS. The books will be well printed on good paper at a price which on the whole is without parallel in the history of publishing. Each volume will contain from Io0 to $35 \circ$ pages, and will be issued in paper covers, crown 8vo, at sixpence net.

4. CLEARNESS OF TYPE. The type will be a very legible one.

5. Simplicity. There will be no editorial matter except a short biographical and bibliographical note by Mr. Sidney Lee at the beginning of each volume.

Where it is possible, each separate book will be issued in one volume, but the longer ones must be divided into several volumes. The volumes may also be obtained in cloth at one shilling net, and where a single book is issued in several sixpenny volumes it may be obtained in cloth in a double or treble volume.

\section{The first Volumes will be:-}

The Works of William Shakespeare. ro Vols.

The Pilgrim's Progress.

The Novels of Jane Austen. 5 Vols.

The Meditations of Marcus Aurelius.

The Decline and Fall of the Roman Empire. 7 Vols.

The Poems of John Milton. 2 Vols.

The Prose Works of John Milton.

The English Works of Francis Bacon.

The Poems and Plays of Oliver Goldsmith.

Select Works of Edmund Burke. 2 Vols.

On the Imitation of Christ.

The Works of Ben Jonson. 12 Vols.

The Works of Henry Fielding. 4 Vols.

The Poems of Chatterton. 2 Vols.

The Plays of Christopher Marlowe. 2 Vols.

The Natural History and Antiquities of Selborne.

The Compleat Angler. 2 Vols.

The Poems of Percy Bysshe Shelley. 4 Vols.

The Works of Sir Thomas Browne. 6 Volse Humphry Clinker.

The Select Works of Sir Thomas More.

The Analogy of Religion.

The Divine Comedy of Dante.

The Early Italian Poets ( 1 roo-1300).

On Human Understanding. By John Locke.

The Poems of John Keats. 2 Vols.

The Lives of the Most Eminent English Poets. By Samuel Johnson. 3 Vols.

Six Dramas of Calderon.

The Adventures of Gil Blas. 2 Vols.

The Life of Samuel Johnson. By J. Boswell. 3 Vols.

The Plays of Philip Massinger.

Travels into Several Remote Nations of the World. By Lemuel Gulliver.

The Diary and Correspondence of Samuel Pepys. 3 Vols.

Adam Bede. 


\section{French}

\section{WORKS BY A. M. M. STEDMAN, M.A.}

Steps to French. Sixth Edition. I8mo, 8d.

First French Lessons. Sixth Edition. Crown 8vo, Is.

Easy French Passages for Unseen Translation. Fifth Edition. Fcap. 8vo, Is. 6d.

Easy French Exercises on Elementary Syntax. With Vocabulary. Second Edition. Crown 8vo, 2s. 6d. Key, 3s. net.

French Vocabularies for Repetition: Arranged according to Subjects. Tenth Edition. Fcap. 8vo, Is.

+ French Examination Papers in Miscellaneous Grammar and Idioms. Twelfth Edition.

A Key, issued to Tutors and Private Students only, to be had on application to the Publishers. Fifth Edition. Crown 8vo, 6s. net.

Easy French Rhymes. By HenRi Blouet. Illustrated. Fcap 8vo, Is.

This little book contains many English nursery rhymes translated into French rhymes. It will supply children with an extensive and easily acquired French vocabulary.

A Junior French Grammar. By L. A. SorNET and M. J. ACATos, Modern Language Masters at King Edward's School, Birmingham. With many Exercises. Crown 8vo, 2s.

+ Junior French Examination Papers in Miscellaneous Grammar and Idioms. By $\bar{F}$. JACOB, M.A., Modern Language Master at Cheltenham College.

* Junior French Prose. By R. R. N. Baron, M.A. Crown 8vo. French Prose Composition. By R. R. N. BARon, M.A. With Vocabularies and Notes. Crown 8vo, 2s. 6d. Key, 3s. net.

Suitable for use in Upper Forms and for Candidates for Army Examinations.

A Manual of French Commercial Correspondence. By S. E. BALLY, late Modern Language Master at the Manchester Grammar School. With Vocabulary. Third Edition. Crown 8vo, 2s.

A French Commercial Reader. By S. E. BAlly. With Vocabulary. Second Edition. Crown 8vo, 2s.

\section{General}

+Junior General Information Fxamination Papers. By W. S. BEARD, Headmaster, The Modern School, Southwold. 
+ General Knowledge Examination Papers. By A. M. M. Stedman, M.A. Fourth Edition.

Key (Third Edition), issued to Tutors and Private Students only, 7s. net. The Rights and Duties of the English Citizen. By $\mathrm{H}$. E. MALDEN, M.A. Is. 6 d.

\section{Geography}

A Historical Geography of the British Empire. By H. B. GEORGE, M.A., Fellow of New College, Oxford. Crown 8vo, 3s. 6d.

The purpose of this work is twofold-to describe in outline the British Empire, with its component parts so grouped as to show forth the diversity of their relations to the mother country -and to point out the nature of the relations between the geography and the history of the British Islands from the beginning, elsewhere from the time of their becoming British possessions, or so much earlier as may be necessary for a clear under. standing of the present conditions.

A Commercial Geography of the British Empire. With special reference to Trade Routes, Manufacturing Districts, etc. By L. W. LYDE, M.A., Professor of Economic Geography, University College, London. Fourth Edition. 2s.

A Commercial Geography of Foreign Nations. By F. C. Boon, B.A., Assistant Master at Dulwich College. Crown 8vo, 2s. Junior Geography Examination Papers. By. W. G. BAKER, M.A. Fcap. 8vo, Is.

* History and Geography Examination Papers. By C. H. Spence, M.A., Clifton College. Second Edition. Crown 8vo, 2s. 6d.

\section{German}

German Vocabularies for Repetition : Arranged according to Subjects. By SopHIE WrighT, late Scholar of Bedford College, London. Fcap. 8vo, Is. 6d.

A Companion German Grammar. By H. DE B. Gibins, Litt.D., M.A. Crown 8vo, Is. 6d.

German Passages for Unseen Translation. By E. M'QueEn Gray. Crown 8vo, 2s, 6d.

+ Junior German Examination Papers. By A. Voegelin, M.A., Assistant Master at St. Paul's School. Fcap. 8vo, Is.

+ German Examination Papers in Miscellaneous Grammar and Idioms. By R. J. MORICH, late Assistant Master at Clifton College. Sixth Edition.

Key (Second Edition), issued to Tutors and Private Students only, 6s. net.

A Manual of German Commercial Correspondence. By S. E. Bally. With Vocabulary. Crown 8vo, 2s. 6d.

A German Commercial Reader. By S. E. Bally. With Vocabulary. Crown 8 vo, $2 \mathrm{~s}$. 


\section{Greek}

\section{TEXTS}

+ The Nicomachean Ethics of Aristotle. Edited, with an Introduction and Notes, by JoHn BuRneT, M.A., Professor of Greek at St. Andrews. Cheaper Edition. Demy 8vo, Ios. 6d. net.

This edition contains parallel passages from the Eudemian Ethics, printed under the text, and there is a full commentary, the main object of which is to interpret difficulties in the light of Aristotle's own rules.

Demosthenes against Conon and Callicles. Edited, with

Notes and Vocabulary, by F. D. SwifT, M.A. Fcap. 8vo, 2s.

Greek Testament Selections. Edited, for the Use of Schools, by A. M. M. Stedman, M.A. Third Edition. With Introduction, Notes, and Vocabulary. Fcap. 8vo, 2s. 6d.

Herodotus: Easy Selections. With Vocabulary. By A. C. LIDDELL, M.A., of Westminster School. Fcap. 8vo, Is, 6d.

\section{TRANSLATIONS}

† Aeschylus - Agamemnon, Chöephoroe, Eumenides. Translated by LeWis CAMPBeli, LL.D. Crown 8vo, 5s.

+ The Frogs of Aristophanes. Translated by E. W. HuntINGFORD, M.A., Professor of Classics in Trinity College, Toronto. Crown 8vo, 2s. 6d.

+ Demosthenes-The Olynthiacs and Philippics. Translated on a new principle by Otho Holland. - Crown 8vo, 2s. 6d.

+ Lucian - Six Dialogues (Nigrinus, Icaro-Menippus, The Cock, The Ship, The Parasite, The Lover of Falsehood). Translated by S. T. Irwin, M.A., Assistant Master at Clifton. Crown 8vo, 3s. 6d.

+ Sophocles-Electra and Ajax. Translated by E. D. A. Morshead, M.A., Assistant Master at Winchester. Crown 8vo, 2s. 6 d.

\section{GRAMMARS, EXERCISES, ETC. WORKS BY A. M. M. STEDMAN, M.A.}

Steps to Greek. Second Edition, Revised. I8mo, rs.

A Shorter Greek Primer. Crown 8vo, Is. 6d.

Easy Greek Passages for Unseen Translation. Third Edition. Fcap. 8vo, Is. 6d.

Greek Vocabularies for Repetition: Arranged according to Subjects. Third Edition. Fcap. 8vo, Is. 6d.

+ Greek Examination Papers in Miscellaneous Grammar and Idioms. Seventh Edition.

Key (Third Edition), issued to Tutors and Private Students only, 6s. net.

+ Junior Greek Examination Papers. By T. C. WeatherHEAD, M.A., Elstree Preparatory School. 
+ Examination Papers in Thucydides. Arranged by $\mathrm{T}$ Nicklin, M.A., Assistant Master at Rossall School. Crown 8vo, 2s. Easy Greek Exercises on Elementary Syntax. By C. G. Botting, B.A., Assistant Master at St. Paul's 'School. Crown $8 \mathrm{vo}, 2 \mathrm{~s}$.

+ Notes on Greek and Latin Syntax. By G. Buckland Green, M.A., Assistant Master at Edinburgh Academy, late Fellow of St. John's College, Oxon. Crown 8vo, 3s. 6d.

Notes and explanations on the chief difficulties of Greek and Latin syntax, with numerous passages for exercise, for the higher forms of schools and the universities.

Passages for Unseen Translation. By E. C. MARCHANT, M.A., Fellow of Peterhouse, Cambridge ; and A. M. Cook, M.A., Assistant Master at St. Paul's School. Second Edition. Crown 8vo, 3s. $6 \mathrm{~d}$.

Two hundred Latin and two hundred Greek passages, arranged in order of increasing difficulty. Has been carefully compiled to meet the wants of V. and VI. form boys at the public schools, and is also well adapted for the use of honourmen at the universities. Prose and verse alternate throughout.

"We know no book of this class better fitted for use in the higher forms of schools." -Guaraian.

+ A Greek Anthology. Selected by E. C. Marchant, M.A., Fellow of Peterhouse, Cambridge. Crown 8vo, 3s. 6d.

+ New Testament Greek. A Course for Beginners. By G. RoDWell, B.A. With a Preface by WALTER LOcK, D.D., Warden of Keble College. Fcap. 8vo, 3s. 6d.

The Greek View of Life. By G, L. Dickinson. Third Edition. Crown 8vo, 2s. 6d.

\section{History}

Makers of Europe. By E. M. WiLmot-Buxton, Assistant Mistress, Brighton and Hove High School. Third Edition, Revised. Crown 8vo, 3s. $6 \mathrm{~d}$.

A text-book of European history suitable for the Middle Forms of Schools. The whole course is designed to fill about two years at the rate of two short lessons a week.

The Ancient World. By E. M. Wilmot-Buxton. With Maps and Illustrations. Crown 8vo, 3s. $6 \mathrm{~d}$.

This book tells the story of the great civilisations of the Ancient World, as made known by recent excavation and discovery, from the dawn of Egyptian history to the days of the Roman Empire. Besides relating important political events, it gives in some detail the literary and social aspects of each country, in order that young students may realise the actual life of the people of those bygone days, and may also take an intelligent interest in such relics of the past as are found in the British Museum.

* Easy Stories from English History. By E. M. WilmotBuXTon. Fcap. 8vo, Is.

The Story of the British Empire for Children. By F. M. ANDERSON. With many Illustrations. Crown 8ro, 2s.

This is a reader containing the story, told simply, of the British Empire. The book falls into two parts. Part I. gives a rapid survey of the colonies and other dependencies of the Empire, with the especial purpose of showing the unity of the whole under the British crown. Part II. deals more extensively with the history and description of India and the four greater states of the Empire-Canada, Australia and Tasmania, New Zealand, and British Africa. 
A Short History of Rome. By J. Wells, M.A., Fellow and Tutor of Wadham College, Oxford. With Three Maps. Fifth Edition. Crown 8vo, 3s. 6d.

"The schoolmasters who have felt the want of a fifth-form handbook of Roman history may congratulate themselves on persuading Mr. Wells to respond to it. His book is excellently planned and executed. Broken up into short paragraphs, with headings to arrest the attention, his manual does equal justice to the personal and the constitutional aspects of the story. Special credit is due to an author who, in the compilation of an elementary work of this kind, faces the difficulties of his subject with conscientious skill, neither ignoring them nor eluding them with a loose phrase, but striving to explain them in the simplest and briefest statements."-Journal of Education.

+ A Constitutional and Political History of Rome. By T. M. TAYLOR, M.A., Fellow of Gonville and Caius College, Cambridge, Porson University Scholar, etc. etc. Crown 8vo, 7s. 6d.

An account of the origin and growth of the Roman institutions, and a discussion of the various political movements in Rome from the earliest times to the death of Augustus.

+ Battles of English History. By H. B. GEORGE, M.A. With numerous Plans. Third Edition. Crown 8vo, 35. 6d.

+ English Records. A Companion to the History of England. By H. E. Malden, M.A. Crown 8vo, 35. 6d.

The French Revolution. By J. E. Symes, M.A. Crown 8vo, 2s. $6 \mathrm{~d}$.

+ History and Geography Examination Papers. By C. H. Spence, M.A., Clifton College. Second Edition. Crown 8vo, 2s. 6d.

+ Examination Papers on the Constitutional and General History of Fngland. By J. TAIT PlowdenWARDLAW, M.A., King's College, Cambridge. Crown 8vo, 2s. 6d.

British Commerce and Colonies from Elizabeth to Victoria. By H. DE B. GibBINS, Litt.D., M.A. Third Edition. Crown 8vo, 2 s.

The Industrial History of England. By H. DE B. GibBins, Litt.D., M.A. Tenth Edition, Revised. With Maps and Plans. Crown 8vo, 3s.

English Social Reformers. By H. DE B. GibBins, Litt.D. Crown 8vo, 2s. 6d.

English Trade and Finance in the Seventeenth Century. By W. A. S. Hewins, B. A. Crown 8vo, 2s. 6 d.

\section{Latin}

\section{TEXTS}

Easy Selections from Caesar. The Helvetian War. With Notes and Vocabulary. By A. M. M. StedmAN, M.A. Illustrated. Second Edition. I8mo, Is.

Elasy Selections from Livy. The Kings of Rome. With Notes and Vocabulary. By A. M. M. STEDMAN, M.A. Illustrated. Second Edition. 18mo, Is, $6 \mathrm{~d}$, 
+ The Captivi of Plautus. Edited, with an Introduction, Textual Notes, and a Commentary, by W. M. Lindsay, Fellow of Jesus College, Oxford. Demy 8vo, ros. 6d. net.

For this edition all the important MSS. have been re-collated. An Appendix deals with the accentual element in early Latin verse. The Commentary is very full.

The Captivi of Plautus. Adapted for Lower Forms by J. H. FreEse, M.A., late Fellow of St. John's, Cambridge. Fcap. 8vo, Is. 6 d.

Taciti Agricola. With Introduction, Notes, Maps, etc. By R. F: DAvis, M.A., late Assistant Master at Weymouth College. Crown 8vo, 2s.

Taciti Germania. By R. F. Davis, M.A. Crown 8vo, 25.

\section{TRANSLATIONS}

+ Cicero-De Oratore I. Translated by E. N. P. Moor, M.A., late Assistant Master at Clifton. Crown 8vo, 3s. 6d.

+ Cicero--Select Orations (Pro Milone, Pro Murena, Philippic II., In Catilinam). Translated by H. E. D. Blakiston, M.A., Fellow and Tutor of Trinity College, Oxford. Crown 8vo, $5 \mathrm{~s}$.

+ Cicero-De Natura Deorum. Translated by F. Brooks, M.A., late Scholar of Balliol College, Oxford. Crown 8vo, 3s. 6d.

Cicero de Officiis. Translated by G. B. Gardiner, M.A. Crown 8 vo, 2s. $6 \mathrm{~d}$.

+ Horace-The Odes and Epodes. Translated by A. GodLey, M.A., Fellow of Magdalen College, Oxford. Crown 8vo, 2s.

+ Thirteen Satires of Juvenal. Translated by S. G. Owen, M.A. Crown 8vo, 2s. 6d.

+ Tacitus-Agricola and Germania. Translated by R. B. Townshend, late Scholar of Trinity College, Cambridge. Crown 8vo, 2s. 6d.

\section{GRAMMARS, EXERCISES, ETC. WORKS BY A. M. M. STEDMAN, M.A.}

Initia Latina : Easy Lessons on Elementary Accidence. Sixth Edition. Fcap. 8vo, Is.

First Latin Lessons. Eighth Edition. Crown 8vo, 2s.

First Latin Reader. With Notes adapted to the Shorter Latin Primer, and Vocabulary. Sixth Edition. 18mo,' Is. 6d.

Easy Latin Passages for Unseen Translation. Ninth Edition. Fcap. 8vo, Is. 6d.

Fxempla Latina: First Exercises in Latin Accidence. With Vocabulary. Third Edition. Crown 8vo, Is.

Easy Latin Fxercises on the Syntax of the Shorter and Revised Latin Primer. With Vocabulary. Ninth Edition. Crown 8vo, Is. 6d. Issued with the consent of Dr. Kennedy. Key, 3s. net. Original Edition. 2s. 6d.

The Latin Compound Sentence: Rules and Exercises. Second Edition. Crown 8vo, Is. 6d. ; with Vocabulary, 2s, 
Notanda Quaedam: Miscellaneous Latin Exercises on Common Rules and Idioms. Fourth Edition. Fcap. 8vo, Is. 6d. ; with Vocabulary, 2s. Key, 2s. net.

Latin Vocabularies for Repetition: Arranged according to Subjects. Eleventh Edition. Fcap. 8vo, Is. 6d.

A Vocabulary of Latin Idioms and Phrases. Second Edition. 18mo, Is.

+ Latin Fxamination Papers in Miscellaneous Grammar and Idioms. Eleventh Edition. Crown 8vo, 2s. 6d. Key (Fourth Edition), issued to Tutors and Private Students only, 6s. net.

+ Junior Latin Examination Papers in Miscellaneous Grammar and Idioms. By C. G. BotTING, B.A., Assistant Master at St. Paul's School. Second Edition. Fcap. 8vo, Is.

† Examination Papers in Horace. Arranged by T. C. Weatherhead, M.A. Crown 8vo, 2s.

† Examination Papers in Vergil. By W. G. COAST, B.A., Assistant Master at Fettes College. Crown 8vo, 2s.

Latin Hexameter Verse. An Aid to Composition. By S. E. Winbolt, M.A., Assistant Master at Christ's Hospital. Crown 8vo, 3s. 6d. Key, 5s. net.

"We may express at once our hearty approval of the method and our faith in its efficacy. The book is so good that the sixth-form master will be unable to dispense with it. To do so will be to handicap himself seriously in the race for scholarships." -Journal of Education.

Exercises in Latin Accidence. By S. E. Winbolt, M.A. Crown 8vo, Is. 6d.

+ Notes on Greek and Latin Syntax. By G. BuckLand Green, M.A., Assistant Master at Edinburgh Academy, late Fellow of St. John's College, Oxon. Crown 8vo, 3s. 6d.

Passages for Unseen Translation. By E. C. Marchant, M.A., Fellow of Peterhouse, Cambridge ; and A. M. Cook, M.A., Assistant Master at St. Paul's School. Second Edition. Crown 8vo, 3s. $6 \mathrm{~d}$.

\section{Mathematics}

Easy Exercises in Arithmetic. Containing 5000 Examples. By W. S. BeARD. Fcap. 8vo. With Answers, Is. 3d. Without Answers, Is.

A course of Arithmetic for lower forms in Secondary Schools and pupils preparing for Public Schools, Naval Cadetships, the Oxford and Cambridge Preliminary Local Examinations. The examples are very numerous, carefully graduated, and do not involve the use of numbers beyond the grasp of young students.

Junior Arithmetic Examination Papers. By W. S. BEARD. With or without Answers. Second Edition. Fcap. 8vo, Is. Contains 900 Questions arranged in papers of ten each.

† Arithmetic Examination Papers. By C. Pendlebury, M.A., Senior Mathematical Master, St. Paul's School. Fifth Edition. With Answers. Crown 8vo, 2s. 6d. Key, 5s. net.

Commercial Arithmetic. By F. G. TAYLOR, M.A. Third Edition. Is. 6 d. 
Technical Arithmetic and Geometry. By C. T. MrLlis, M.I.M.E., Principal of the Borough Polytechnic Institute. With Diagrams. Crown 8vo, 3s. 6d.

In this book the author has constantly brought before his reader the practical applications of the problems or calculations he is discussing, and almost every page has a direct bearing on workshop life.

A South African Arithmetic. By Henry Hill, B.A., Headmaster, Boys' High School, Worcester, Cape Colony. Cr. 8vo, 3s.6d. A Junior Geometry. By Noel S. Lydon of Owen's School, Islington. With 239 Diagrams and numerous Exercises. Cr. 8vo, 2s. "We do not know any book for beginners which deserves higher commendation."-
Nature.

"A good course. The exercises are plentiful and well chosen, especially the graphical ones."-Journal of Education.

Geometry on Modern Lines. By E. S. Boulton, M.A., Lecturer in Mathematics at Merchant Venturers' Technical College, Bristol. Crown 8 vo, 2 .

Test Cards in Euclid and Algebra. By D. S. CALderwood, Headmaster of the Normal School, Edinburgh. In three packets of 40, with Answers. Is. each ; or in three books, price 2d., 2d., and $3 \mathrm{~d}$. Junior Algebra Examination Papers. By S. W. FINN, M.A., Headmaster, Sandbach School. With or without Answers. Fcap. 8vo, Is.

The Principles of Book-keeping by Double Entry. By J. E. B. M‘Allen, M.A. Crown 8vo, 2s.

+ Examination Papers in Book-keeping. With Prelim. inary Exercises. Compiled and Arranged by J. T. Medrurst, F.S.Accts. and Auditors, and Lecturer at City of London College. Seventh Edition. Crown 8vo, 3s. Key, 2s. 6d. net.

+ Trigonometry Examination Papers. By G. H. WARD, M.A., late Assistant Master at St. Paul's School. Fourth Edition. Crown 8vo, 2s. 6d. Key, 5s. net.

The Metric System. By LeON Delbos. Crown 8vo, $2 \mathrm{~s}$.

A theoretical and practical Guide, for use in elementary schools and by the general reader. Contains a number of Graduated Problems with Answers.

\section{Science.}

Elementary Experimental Science. - PHysics, by W. T Clough, A.R.C.S. ; Chemistry, by A. E. DUNSTAN, B.Sc. With 2 Plates and 154 Diagrams. Crown 8vo, 2s. 6d:

"This useful work includes the elements of general physics, heat, and chemistry, which are treated with commendable simplicity, clearness, and accuracy. Some of the tips are especially good. The diagrams are clear, the worked examples are typical, and the set of tables very convenient." -University Correspondent.

General Elementary Science. By J. T. DunN, D.Sc., and V. A. Mundella, M.A. With II 4 Illustrations. Crown 8vo, 35. 6d. Specially intended for London Matriculation Examination. Adopted by the Admiralty.

The World of Science. Including Chemistry, Heat, Light, Sound, Magnetism, Electricity, Botany, Zoology, Physiology, Astronomy, and Geology. By R. ELLIOT STEEL, M.A., F.C.S. I47 Illustrations. Second Edition. Crown 8vo, 2s. 6d. 
* Elementary Experimental Chemistry. By A. E. DuNsTAN, B.Sc., Head of the Chemical Department, East Ham Technical College. With many Illustrations. Crown 8vo.

A Junior Chemistry. By E. A. Tyler, B.A., F.C.S., Head of the Chemical Department, Swansea Technical College. With 73 Illustrations. Crown 8vo, 2s. 6 d.

Practical Chemistry. By W. FRENCH, M.A., Principal of the Storey Institute, Lancaster. Part I. With 57 Diagrams. Second Edition. Crown 8vo, Is. 6d. Part II. By W. FRENCH, M.A., and T. H. Boardman, M.A., Science Master at Christ's Hospital, Crown 8vo, Is. 6d.

Based on the scheme issued by the Education Department for Evening Continuation Schools and that of the Headmasters' Association. Suitable for Oxford and Cambridge Junior Locals. The teaching throughout is inductive.

Practical Mechanics. By Sidney H. Wells. With 75 Illustrations and Diagrams. Second Edition. Crown 8vo, 3s. 6d.

Contains all that is necessary for the London Matriculation Examination and the Elementary course in Applied Mechanics of the Science and Art Department.

Practical Physics. By H. STRoud, D.Sc., M.A., Professor of Physics in the Durham College of Science, Newcastle-on-Tyne. With 115 Diagrams. Crown 8vo, 3s. 6d.

An introduction to the standard works on Practical Physics.

* A Junior Magnetism and Electricity. By W. T. Clovgr, A.R.C.S.(Lond.), Head of the Physical Department, East Ham Technical College. Crown 8vo.

A Class Book on Light. By R. E. STEEL. With numerous Illustrations. Crown 8vo, 2s. 6d.

The Principles of Magnetism and Electricity. By P. L. GraY, B.Sc. With I8I Diagrams. Crown 8vo, 3s. 6d.

"A capital text-book. One which we can recommend with the utmost confidence."Teachers' Review.

"Perfectly reliable."-Educational Times.

+ Physics Examination Papers. By R. E. Steel, M.A., F.C.S., Headmaster, County School, Northampton. Papers on Sound, Light, Heat, Magnetism, Electricity.

+ The Scientific Study of Scenery. By J. E. MARR, M.A., F.R.S., Fellow of St. John's College, Cambridge. With numerous Illustrations and Diagrams. Second Edition. Crown 8vo, 6s.

Agricultural Geology. By J. E. MARR, F.R.S. With numerous Illustrations. Crown $8 \mathrm{vo}, 6 \mathrm{~s}$.

Agricultural Zoology. By Dr. J. Ritzema Boz. Translated by J. R. AinsworTh DAvis, M.A. With I55 Illustrations. Second Edition, with full Index. Crown 8vo, 3s. 6 d.

Dairy Bacteriology. A Short Manual for the Use of Students. By Dr. ED. VON FREUDENREICH. Translated by J. R. AINSWORTH Davis, M.A. Second Edition. Crown 8vo, 2s. 6d.

+ Outlines of Biology. By P. Chalmers Mitchell, M.A. Illustrated. Second Edition. Crown 8 vo, $6 \mathrm{~s}$.

A text-book designed to cover the new Schedule issued by the Royal College of Physicians and Surgeons. 


\section{UNIYERSITY EXTENSION SERIES}

Crown 8vo, 2s. 6d. (with two exceptions)

These books are suitable for extension students and home reading circles. Each volume is complete in itself, and the subjects are treated by competent writers in a broad and philosophic spirit.

The Evolution of Plant Life. By G. MASSEE.

Air and Water. By Prof. V. B. LEWES, M.A. Illustrated. The Chemistry of Life and Health. By C.W. Kimmins, M.A. The Mechanics of Daily Life. By V. P. SElls, M.A. The Chemistry of Fire. By M. M. PatTison Muir, M.A. A Text-Book of Agricultural Botany. By M. C. PotTER, M.A., F.L.S. Illustrated. Second Edition. 4s. 6d.

The Vault of Heaven. By R. A. GREGORY.

Meteorology. The Elements of Weather and Climate. By H. N. Dickson, F.R.S.E., F.R.MET.Soc. Illustrated.

A Manual of Electrical Science. By G. J. BURCH, M.A., F.R.S. Illustrated. 3s.

The Earth : An Introduction to Physiography. By Evan SmalL, M.A. Illustrated.

\section{Technology.}

Carpentry and Joinery. By F. C. WEBBER. With I76 Illustrations. Fourth Edition. Crown 8vo, 3s. $6 \mathrm{~d}$.

The drawings are intended to serve not only as illustrations, but also as examples lor reproduction by the student.

"An admirable elementary text-bouk on the subject."-Builder.

Builders' Quantities. By H. C. GRUBB, Lecturer on Quantities to the Beckenham Technical Institute, First Honoursman City and

Guilds of London Institute. With 73 Diagrams. Crown 8vo, 45. 6d.

"The book can be recommended to all who wish to commence studying this subject as a lucid, concise, and comprehensive account, and Mr. Grubb is to be congratulated on his success."-Manual Training Teacher.

"The author treats the subject in a simple and yet adequate manner. The illustrations are clearly drawn and well reproduced." - Technics.

† The Construction of Large Induction Coils. By A. T. HARE, M.A. With numerous Diagrams. Demy $8 \mathrm{vo}, 6 \mathrm{~s}$.

An Introduction to the Study of Textile Design. By A. F. BARKER, Head of the Department of Textile Industries, Bradford Technical College. Demy 8vo, 7s. 6d.

"Altogether it is careful and painstaking, and will be regarded as indispensable in textile colleges, while for manufacturers it has a distinct value."-Bradford Telegraph.

"A thoroughly practical manual." - Scotsman.

† Ornamental Design for Woven Fabrics. By C. StePheNson, of the Technical College, Bradford ; and F. SUDDARDS, of the Yorkshire College, Leeds. With 65 full-page Plates. Second Edition. Demy 8vo, 7s. 6d.

* Solutions to the City and Guilds Questions in Manual Instruction: Drawing. (First Year Papers.) By F. STURCH, Manual Training Instructor to the Surrey County Council. Imp. 4to.

Printed by MORRISON \& GibB Limited, Edinburgh. 



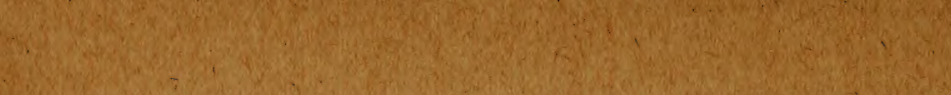

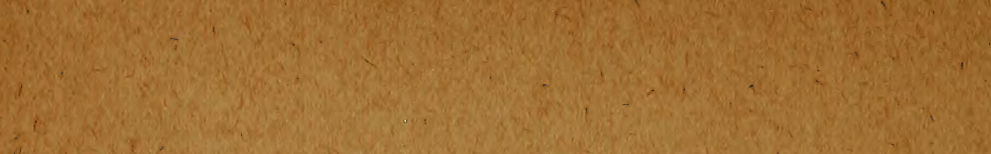

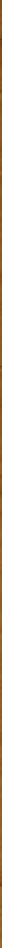




$$
\text { tith } 62
$$


SMITHSONIAN INSTITUTION LIBRARIES

||||||||||||||||||||||||||||||||||||||||||||||||||||||||||||||||||||||

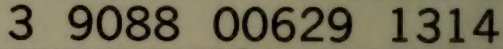

